\title{
The Risk of Dietary Exposure to Pesticide Residues and Its Association with Pesticide Application Practices among Vegetable Farmers in Arusha, Tanzania
}

\author{
Purificator Andrew Kiwango ${ }^{1}$, Neema Kassim ${ }^{1} \&$ Martin Epafras Kimanya ${ }^{1,2}$ \\ ${ }^{1}$ Department of Food Biotechnology and Nutritional Sciences, School of Life Sciences and Bioengineering, The \\ Nelson Mandela African Institution of Science and Technology, P.O. Box 447, Arusha. Tanzania \\ ${ }^{2}$ Department of Rural Economy and Agriculture, African Union Commission, P.O. Box 3243, Addis Ababa, \\ Ethiopia \\ Correspondence: Purificator Andrew Kiwango, Department of Food Biotechnology and Nutritional Sciences, \\ School of Life Sciences and Bioengineering, The Nelson Mandela African Institution of Science and Technology, \\ P.O. Box 447, Arusha. Tanzania. Tel: 255-7634-07361. E-mail: puriandrew@ gmail.com; puriand@ yahoo.com
}

Received: October 27, 2017 Accepted: November 14, 2017 Online Published: February 19, 2018

doi:10.5539/jfr.v7n2p86 URL: https://doi.org/10.5539/jfr.v7n2p86

\begin{abstract}
This study was conducted to assess dietary exposure to pesticide residues and pesticide application practices leading to the presence of these residues among vegetable farmers in Arusha, Tanzania. Face-to-face interviews using semi-structured questionnaires (including 24-hour recall and food frequency questionnaire techniques) were conducted to collect information on pesticide application practices and vegetable consumption, from 76 farmers. A sample of ready-to-eat vegetables was collected from each farmer's household to determine the level of pesticide residues. Pesticide residues were analyzed by gas chromatography-mass spectroscopy

A deterministic approach was used to assess dietary exposure to pesticide residues. Among the analyzed samples, $31.4 \%$ contained detectable levels of organophosphate residues. The detected organophosphates were dimethoate (mean, $8.56 \mathrm{mg} \mathrm{kg}^{-1}$ ), acephate (mean, $2.9 \mathrm{mg} \mathrm{kg}^{-1}$ ), profenofos (mean, $8.44 \mathrm{mg} \mathrm{kg}^{-1}$ ), dichlorvos (mean, $20.8 \mathrm{mg}$ $\left.\mathrm{kg}^{-1}\right)$ and malathion (mean, $\left.5.47 \mathrm{mg} \mathrm{kg}^{-1}\right)$. The mean exposure for dimethoate $\left(0.0021 \mathrm{mg} \mathrm{kg}^{-1}\right.$ body weight (wt) day $^{-1}$ was higher than its corresponding acceptable daily intakes of $0.002 \mathrm{mg} \mathrm{kg}^{-1} \mathrm{bwd}^{-1}$ resulting in hazard quotient of 1.044 with a consequent hazard index of 1.19 for organophosphates. Pyrethroid pesticides (permethrin, cypermethrin, and lambda-cyhalothrin) were also detected but at a lower frequency $(17.1 \%)$ and hazard index (0.029). The exposure to pesticide residues was significantly associated with limited access to expert advice on pesticide application $(p=0.031$, adjusted odds ratio $=6.56)$ and over-dosage $(p=0.038$, adjusted odds ratio $=3.751$ ). The risk may be minimized by increasing access to support by extension service providing guidance on good practices and ensuring application of appropriate doses for pesticides.
\end{abstract}

Keywords; pesticide residue, exposure, ready-to-eat, application practices, vegetable farmers, organophosphates, pyrethroids, agricultural extension officers, over-dosage

\section{Introduction}

Malpractices in pesticides application result to unacceptable levels of pesticide residues in foods, and consequently increase the risk of unsafe dietary pesticide exposures in humans. Dietary exposure to unacceptable levels of pesticide residues has been associated with risks of developing cancer, genetic and immune system defects and neurological system disorders (Hashmi, Imran, \& Dilshad, 2004; Keifer., 2008; Thatheyus \& Gnana Selvam, 2013). Parkinson's and Alzheimer's diseases are the most common neurodegenerative disorders which are associated with exposure to pesticides (Campdelacreu, 2012; Sanchez-Santed, 2015). Pesticides possess estrogenic activity and therefore are associated with breast cancers in women and low sperm count in males (Laffin, Chavez, \& Pine, 2010; Toft, Hagmar, Giwercman, \& Peter, 2004). To ensure the pesticide safety of vegetables and other foods, Codex Alimentarius Commission in collaboration with Environmental Protection Agency (EPA) has set maximum tolerable residual levels (MRLs) for particular pesticides in food including vegetables (European Food Safety Agency [EFSA], 2012; Food and Agriculture Organization [FAO]/World Health Organization [WHO], 1997). 
Vegetables form an important part of human diet, however, are food crops with a very high likelihood of containing pesticides. Surveys in developing countries indicate that in vegetables there is an indiscriminate use of pesticides for pest and disease control, combined with non adherence to pesticides' pre-harvest intervals, and lack of knowledge of the correct use of pesticides, all of which could likely result in excessive levels of pesticide residues in vegetables (Amera \& Abate, 2008; Banjo, Aina, \& Rije, 2010; Lozowicka et al., 2015; Zyoud et al., 2010). A study done in Chile revealed that $27 \%$ of 118 leafy vegetable samples analyzed were contaminated with pesticide residues above MRLs and 65\% of them had multiple pesticide residues (Elgueta, Moyano, Sepúlveda, \& Quiroz, 2017). A study by Sheikh, Nizamani, Panhwar \& Miran (2013) in Pakistan which analyzed pesticide residues in vegetable samples from markets found that okra, bitter gourd, brinjal, tomato, onion, cauliflower, and chilies were highly contaminated with chlorpyrifos, profenofos, endosulfan, imidacloprid, benzoate, lufenuron, bifenthrin, diafenthiuron, and cypermethrin. Another study analyzed dichlorvos residue levels in vegetables sold in Lusaka, Zambia and found that the average dichlorvos residue levels were significantly higher than the country's set maximum limits $\left(1 \mathrm{mg} \mathrm{kg}^{-1}\right)$ (Sinyangwe, Mbewe, and Sijumbila, 2016). High pesticide residue levels in vegetables imply that those consuming vegetables might be at risk of exposure to unacceptable levels of pesticides. In order to ensure that dietary exposures to pesticide residues are within safe limits, the FAO/WHO Joint Meeting of Pesticide Residues (JMPR) establishes acceptable daily intakes (ADI) of pesticides (FAO/WHO, 1997). For instance, the ADI for dimethoate is $0.002 \mathrm{mg} \mathrm{kg}^{-1}$ body weight and that of dichlorvos is $0.004 \mathrm{mg} \mathrm{kg}^{-1}$ body weight. Malathion which is relatively less toxic has an ADI of $0.3 \mathrm{mg} \mathrm{kg}^{-1}$ body weight.

Tanzania as a developing country is affected by the problem of malpractices in pesticide application. Evidence from surveys conducted in Southern highlands (Iringa), Central (Morogoro) and Northern zones (Arumeru and Karatu) confirms this (Lekei, Ngowi, and London, 2014a; Manyilizu \& Mdegela, 2015; Ngowi, Mbise, Ijani, London \& Ajayi, 2007; Nonga, Mdagela, Sandvik \& Skaare, 2011). These studies suggest that vegetables from these areas may be highly contaminated with pesticide residues, posing a risk of exposure to pesticide residues. However, only limited studies have been done in Tanzania to estimate pesticide residues or exposure in vegetables. A study by Ndengario-Ndossi and Cram, (2005) which analysed 33 samples of spinach found that $72.7 \%$ of the samples were contaminated with gamma-hexachlorocyclohexane $(\mathrm{g}-\mathrm{HCH})\left(0.08 \mu \mathrm{g} \mathrm{kg}^{-1}\right)$, 1,1-dichloro-2,2-bis (p-chlorophenyl) ethylene (pp-DDE) $\left(0.74 \mu \mathrm{g} \mathrm{kg}^{-1}\right)$, dichlorodiphenyltrichloroethane (pp-DDT) $\left(2.15 \mu \mathrm{g} \mathrm{kg}^{-1}\right)$ and chlorpyrifos $\left(0.02 \mu \mathrm{g} \mathrm{kg}^{-1}\right)$. Mahugija, Khamis \& Lugwisha (2017) analyzed 72 samples of cabbage, onion, and spinach for pesticide residues in which $72.2 \%$ of the vegetables were found to be contaminated with DDT and its metabolites, endosulfan, and cypermethrin. However, these two studies were done in Dar es Salaam, which is not a major vegetable producing area in Tanzania. In this country, vegetables are mainly produced in highlands of Morogoro, Iringa, and Arusha (Putter \& Koesveld, 2007; Small \& Medium Enterprise Competitiveness Facility [SCF], 2008), of which Arusha leads in pesticide trading and use (Agenda, 2006). The reported levels of pesticide residues in the vegetables sampled in markets in Dar es Salaam indicate that farmers in major vegetable producing areas such as Arusha might be exposed to high levels of pesticide residues. A study in Arumeru district in Arusha analyzed 50 tomato samples for pesticide residues and 12\% of the samples contained permethrin and chlorpyrifos at mean concentrations of $5.2899 \mathrm{mg} \mathrm{kg}^{-1}$ and $7.5281 \mathrm{mg} \mathrm{kg}^{-1}$, respectively (Kariathi, Kassim, \& Kimanya, 2016). However, the results from this work are not adequate for drawing a conclusion on the dietary exposures through vegetables in Arusha as there are more varieties of vegetables consumed in the region. Furthermore, in Tanzania and other developing countries, there is no documented information on specific pesticide application practices that can be attributed to pesticide residues. The current study assessed pesticide residue exposures through vegetable consumption among vegetable farmers in Arusha and determined pesticide application practices attributable to the exposures.

\section{Materials and Methods}

\subsection{Study Area}

The study was conducted in one district of the Arusha region. The Arusha district in Arusha region was selected due to its high production of vegetables and known pesticide use (Agenda, 2006). The district covers an area of $1446.692 \mathrm{~km}^{2}$ with a population of 290,041 . It is characterized by two agricultural zones (green and low land belt zones). The main vegetable producing areas of the Arusha district are in the green belt (highlands), which covers the wards of Ilkiding'a, Kimnyaki, Kiranyi, Sambasha, and Olmotonyi. The main vegetable crop cultivated in Arusha is cabbage. Due to its high vulnerability to pest infestation, the crop requires frequent application of pesticides (Ngowi et al., 2007; United Republic of Tanzania [URT], 2012).

\subsubsection{Study Design and Sample Size}

A cross-sectional study design was adopted to survey pesticide residues, exposure, and application by 76 farmers 
selected by simple random technique, from seven villages in four wards of the green belt zone of the Arusha district. At ward level, village(s) leading in vegetable farming were purposively selected as follows: Ilkiding'a (Ilkiding'a), Olimring'aring'a and Olevolous (Kimnyaki), Siwandeti (Kiranyi), Timbolo and Shiboro (Sambasha) and Emaoi (Olmotonyi). The wards were purposively identified, with the assistance of district agricultural extension officers, based on their potential for vegetable production.

The sample size was estimated at $90 \%$ confidence level, following the formula for calculating sample size for cross sectional studies (Charan \& Biswas, 2013). Farmers participating in this study were selected using a set of criteria. Of the criteria used was the willingness of a farmer to participate in the research during the field survey and his/her availability during both the first and the second vegetable consumption surveys. Farmers were pre-informed of the objectives of the research and those who consented to participate in the study were recruited.

\subsubsection{Data Collection}

Data collection was done from June to November 2015 (a period that covers dry and rainy seasons) during face to face interviews. Semi-structured questionnaires were used in the interviews to obtain information on socio-demographic characteristics of the participants, the vegetable cropping system used, pesticide application practices and vegetable consumption. Detailed information on vegetable consumption was further collected using two-time point 24-hour dietary recall and food frequency questionnaires. Prior to actual data collection, the questionnaires were pre-tested in Seela village of Sing'isi ward which is in a similar geographical location and of the same socio-cultural characteristics to those of the study area.

\subsection{Sampling and Quantification of Ready-to-eat Vegetables}

Repeated 24 hours dietary recall and food frequency techniques were employed to estimate the amount of vegetables consumed by the farmers (Kimanya et al., 2009). Two home visits were conducted, on non-consecutive days. The respondent farmer was requested to recall what she/he ate during the past 24 hours. If vegetables were among what she/he consumed, she/he was requested to mention the type of vegetables consumed. The respondent was also requested to mention the source of the consumed vegetables, whether from her/his own farm, a neighbour's farm or a market. The respondent was further asked to mention the number of days in the previous week during which she/he ate the same type of vegetables.

The respondent was requested to explain how the vegetable was prepared and mention all ingredients in the vegetable recipe. She/he was also requested to estimate the amount of ready-to eat-vegetable consumed during the previous day, by using a bowl or any other utensil that is usually used for serving vegetables. Grains or pulses were used to aid in estimating the vegetable volumes of the bowl by filling into the bowl up to the usual level of the share per single serving. The left-over or shared amounts were deducted from the volume served per single serving and the actual estimate obtained and noted. The respondent was requested to prepare vegetables and provide a duplicate portion (per serving) of the ready-to-eat vegetables as reported in the interview. Arrangements were made for those who had no vegetables in their home at the time of survey so that the samples were collected on the next day. The sample of the ready-to-eat vegetables was then collected in a glass container and kept in a cool box with ice blocks and transported to the Tropical Pesticide Research Institute (TPRI) laboratory where its weight was measured using an electronic kitchen scale (CAMRY, model EK3131) and recorded before it was stored at $-20^{\circ} \mathrm{C}$ in a freezer until analysed for pesticide residues. The average weight of vegetable consumed by each respondent as collected during the two home visits was calculated and recorded.

Respondents who reported that they had not consumed vegetables on the previous day were requested to estimate the amount that they usually consume, and the duplicate sample was measured based on this amount. In order to be able to estimate per capita vegetable consumption per kg body weight per day, the weight of the respondent was taken using a weighing scale (Ashton Meyers' model 7757; maximum scale $130 \mathrm{~kg}$ ) and recorded.

\subsection{Analysis of Pesticide Residues in Ready-to-eat Vegetables}

\subsubsection{Chemicals and Reagents}

All chemicals and reagents were of analytical grade. Pesticide standards (96\% or more purity) were obtained from various suppliers, namely Ciba-Geigy Ltd. for profenofos and cypermethrin, Calliope rural Traders, Australia for lambda-cyhalothrin, Sapa chemicals industries Ltd Tanzania for malathion, Dow AgroSciences France for dimethoate, Baytrade Tanzania Ltd for acephate, Novartis S.A. for dichlorvos, Zeneca Agrochemicals for permethrin and Twiga Chemicals Ind. Ltd. Tanzania for heptachlor. Solvents (acetonitrile, acetic acid, and acetone), salts (sodium acetate, magnesium sulphate and sodium sulphate ) Primary Secondary Amine (PSA), glassware, centrifuge tubes and GC-MS vials were obtained from a local dealer Smacco-Flo General Supplies, 
Arusha. All glassware was washed with a detergent dissolved in water and rinsed with distilled water followed by acetone, before and after each use. Centrifuge tubes and GC-MS vials were non-recyclable.

\subsubsection{Pesticide Residue Extraction and Analysis}

Pesticide extraction and clean-up were done following the QuEChERS Protocol (AOAC, 2007) . Briefly, samples were removed from the freezer and brought to room temperature before homogenization. After homogenization using a motor and pestle, $15 \mathrm{~g}$ of a sample was weighed into a $50 \mathrm{ml}$ polypropylene centrifuge tube and extracted using acetonitrile with $1 \%$ acetic acid $(1: 10 \mathrm{v} / \mathrm{v} \mathrm{ml}) .15 \mathrm{ml}$ of the solvent followed by $100 \mu \mathrm{l}$ or $200 \mu 1$ of $1 \mathrm{mg} \mathrm{ml}^{-1}$ or $0.1 \mathrm{mg} \mathrm{ml}^{-1}$ heptachlor as an internal standard were added to the sample followed by $6 \mathrm{~g}$ of anhydrous magnesium sulphate and $1.5 \mathrm{~g}$ sodium acetate. The mixture was then centrifuged in a Universal 320 centrifuge from Andreas Hettick GmbH Co KG, Tuttlingen Germany, at $536.64 \mathrm{xg}$ for 5 minutes. Three millilitres of the supernatant was transferred to a $15 \mathrm{ml}$ polypropylene centrifuge tube containing $600 \mathrm{mg}$ anhydrous magnesium sulphate, $150 \mathrm{mg}$ primary secondary amine (PSA) and $150 \mathrm{mg}$ graphitized carbon and homogenized on a vortex mixer (Vortex Genie-2 from Bohemia, USA). The mixture was centrifuged at 536.64 $\mathrm{x} g$ for 5 minutes, and $2 \mathrm{ml}$ of the supernatant transferred to the GC-MS vial for analysis of pesticide residues.

Pesticide residues were analyzed by GC-MS (Agilent 7890A equipped with 7693 auto-sampler coupled to 7000B triple quadruple MS system). The column was a fused silica DB35 capillary column $30 \mathrm{~mm}$ long with a $0.25 \mathrm{~mm}$ internal diameter and a $0.25 \mu \mathrm{m}$ film capable of operating at a range of $50^{\circ} \mathrm{C}$ to $360^{\circ} \mathrm{C}$. The temperature was set at $50{ }^{\circ} \mathrm{C}$ for 1 minute, then raised to $150^{\circ} \mathrm{C}$ at a rate of $50{ }^{\circ} \mathrm{C}$ per minute for 1 minute, followed by $280{ }^{\circ} \mathrm{C}$ at a heating rate of $5{ }^{\circ} \mathrm{C}$ per minute and held for four minutes. The injector temperature was $250{ }^{\circ} \mathrm{C}$. The carrier gas was helium at a flow rate of $1.2 \mathrm{ml} \mathrm{min}^{-1}$ splitless injection. The injection volume was $1 \mu \mathrm{l}$ at a pressure of 43.193 Psi. The MS ion source temperature was $250{ }^{\circ} \mathrm{C}$ operated in full scan mode at a scan range of $50-5500^{\circ} \mathrm{C}$ atomic mass unit.

\subsection{Method Performance and Quality Assurance}

The method performance was validated according to the European Commission guidelines (SANCO, 2014) by performing analyses to determine recovery, limit of detection (LOD), limit of quantification (LOQ), precision and linearity. Recovery was performed by analyzing, in triplicate, a mixture of standard pesticides in blank vegetable samples at levels of $0.0050,0.0100$ and $0.0200 \mathrm{mg} \mathrm{kg}^{-1}$. These levels are below or above the MRLs of most of the pesticides approved for use in horticultural crops in Tanzania, and therefore could provide information on performance of the method at a range of the concentrations below, at, and above the MRLs of the pesticide residue in the vegetables. LOD was determined as the lowest concentration of the pesticide that could be detected but not quantifiable. LOQ was determined as the lowest concentration that could be quantified at acceptable accuracy and linearity. LOD and LOQ were determined as 1:3 and 1:10 signal to noise ratio, respectively. Precision was determined by calculating relative standard deviation (rsd) of the lowest concentration that could show linearity $(n=5)$ in blank vegetable sample, whereas linearity was assessed by analyzing a mixture of pesticide standards at $0.005,0.0075,0.01,0.0125,0.0150,0.0175$ and $0.0200 \mathrm{mg} \mathrm{kg}^{-1}$. The routine quality control was done by adding heptachlor as an internal standard in each analytical sample and calculated percentage recovery. Blank reagents were analyzed at the beginning and end of each batch to check for interference from chemicals and equipment. The concentration of pesticides analyzed was quantified from their corresponding calibration curves.

\subsection{Estimating Dietary Pesticide Residue Exposure}

Dietary exposure $\left[\mathrm{mg} \mathrm{kg}^{-1}\right.$ body weight (bw) per day] of a pesticide residue in an adult vegetable farmer was determined following the deterministic approach as guided by WHO and FAO (FAO/WHO, 2009). The exposure was estimated by multiplying concentration of the pesticide residue $\left(\mathrm{mg} \mathrm{kg}^{-1}\right)$ in the vegetable sample (from the farmer's household) with the estimated amount of vegetable consumption by the individual $\left(\mathrm{kg} \mathrm{day}^{-1}\right)$ and dividing by bw $(\mathrm{kg})$ of the individual as shown in equation 1

$$
E D I=\frac{Q(k g / d a y) x C(m g / k g)}{b w(k g)}
$$

Where EDI is the estimated daily dietary intake of the pesticide residue in milligram per kilogram body weight of the consumer, $\mathrm{Q}$ is the quantity of vegetable consumed per day ( $\mathrm{kg}$ per day) and $\mathrm{C}$ is the concentration of the residue in the vegetable in $\mathrm{m} \mathrm{kg}^{-1}$. 


\subsubsection{Estimating the Risk of Unacceptable Exposures}

Risk of unacceptable exposure to a particular pesticide residue was determined by calculating the hazard quotient of such particular pesticide using the equation described by JMPR (2005) and USEPA (2005) (equation 2):

$$
H Q=\frac{E D I}{A D I}
$$

Where: HQ is the hazard quotient, EDI is the estimated daily intake $\left(\mathrm{mg} \mathrm{kg}^{-1} \mathrm{bw} \mathrm{day}{ }^{-1}\right)$ of a particular pesticide and ADI is the corresponding acceptable daily intake $\left(\mathrm{mg} \mathrm{kg}^{-1} \mathrm{bw} \mathrm{day}^{-1}\right)$ for the pesticide.

For multiple exposures to pesticide residues falling under the same chemical group (same mechanism of toxicity) such as organophosphates or pyrethroids, the risk of exposure was calculated by adding the HQs of pesticide residues of the same chemical group to obtain the hazard index, using equation 3 (EFSA, 2008; FAO/WHO, 2005; USEPA, 2005).

$$
H I=\frac{E D I a}{A D I a}+\frac{E D I b}{A D I b}+\ldots \frac{E D I n}{A D I n}
$$

Where: $\mathrm{HI}$ is the hazard index, $a, b \ldots n$ represent different pesticides of the same mechanism of toxicity, EDI is the estimated daily intake of each pesticide and ADI is the corresponding acceptable daily intake. HQ or HI $\leq 1$ indicates that adverse health effect(s) are not likely to occur and thus the amount of pesticide residue consumed can be considered tolerable. HQ or HI > 1 denotes that the exposure is greater than ADI and that there might be a risk from the residue consumed, a situation which calls for a risk management action to be taken (FAO/WHO, 2005; United States Environmental Protection Agency [USEPA], 2005). Exposure in farmers who consumed vegetables with undetectable pesticide residues was performed by assigning a default value of half the limit of detection for each pesticide (middle bound scenario), according to the US-EPA's Office of Pesticide Programs (USEPA, 2000).

\subsection{Data Analysis}

Data entry and clean-up for pesticide application practices were done using Epidata version 3.1, a free downloadable software owned by WHO which was obtained from The Tanzania National Institute for Medical Research (NIMR). The data were then exported to Microsoft Excel 2007 and SPSS version 21 for analysis. Data for pesticide residue content, vegetable consumption and body weight were used to calculate and estimate daily intakes and risk of exposure using equations ' $l$ ' to ' 3 ' of this section. Descriptive statistics (frequency and percentage) were used to interpret information captured from questionnaires. Logistic regression was used to analyze the association between level of education, the source of vegetables (between home-grown and market or neighbour sourced), or pesticide application practices and exposures of pesticide residues to farmers. The significance level of association was set at $\mathrm{p} \leq 0.05$.

\section{Results and Discussion}

\subsection{Method Performance and Quality Assurance}

Average recoveries of all pesticide standards in sample matrices ranged from $79 \%$ to $112 \%$ indicating that the results obtained are reproducible. Limits of detection ranged from 0.001 to $0.004 \mathrm{mg} \mathrm{kg}^{-1}$ whereas limits of quantification ranged from 0.002 to $0.015 \mathrm{mg} \mathrm{kg}^{-1}$ which shows that the sensitivity of the method is good enough for detection and quantification of pesticide residues in the vegetable samples below the set MRLs for most of the pesticides. The percent rsd ranged from $1.02 \%$ to $18.6 \%$ and coefficient of correlation was between 0.955 and 0.999 (Table1) showing good repeatability of the method. Recovery for heptachlor (added to each analytical sample to check for the on-going performance of the method) ranged from $70 \%$ to $132 \%$ with an average of $95 \%$. No corrections made to the concentration of residues in the samples as the recoveries were within the recommended range. It is recommended that for on-going method performance verification, recovery should range from 60\%-140\% (SANCO, 2014). No pesticide residues detected in the blank chemical reagents which indicate that there was good control of interferences from chemicals and instruments. These results indicate that the method was reliable for analysis of the pesticide residues of interest in the ready-to-eat leafy vegetables. For a method to be reliable, initial method validation recovery should be between 70 and $120 \%$, percent rsd not higher than 20\% and coefficient of correlation equal to or higher than 0.95 (Kofi Akomeah, Akuamoa, Frimpong \& Buah-kwofie, 2016; SANCO, 2014). 
Table 1. Results of QuEChERS multi-residues method validation in leafy vegetables

\begin{tabular}{llllll}
\hline Analyte & $\mathrm{LOD}\left(\mathrm{m} \mathrm{kg}^{-1}\right)$ & $\mathrm{LOQ}\left(\mathrm{mg} \mathrm{kg}^{-1}\right)$ & $\mathrm{r}^{2}$ & Mean recovery $(\%)$ & $\mathrm{rsd} \%(\mathrm{n}=5)$ \\
\hline Permethrin & 0.001 & 0.005 & 0.997 & 88.01 & 13.9 \\
Cypermethrin & 0.002 & 0.006 & 0.999 & 92.52 & 9.60 \\
Cyhalothrin & 0.001 & 0.005 & 0.992 & 112.3 & 13.6 \\
Dimethoate & 0.004 & 0.015 & 0.955 & 89.98 & 9.93 \\
Acephate & 0.003 & 0.009 & 0.960 & 78.86 & 18.6 \\
Profenofos & 0.004 & 0.010 & 0.992 & 91.12 & 1.02 \\
Malathion & 0.001 & 0.002 & 0.995 & 83.15 & 12.2 \\
Dichlorvos & 0.004 & 0.010 & 0.995 & 100.2 & 1.70 \\
Heptachlor & 0.001 & 0.030 & 0.999 & 102.0 & 9.80 \\
\hline
\end{tabular}

\subsection{Socio-demographic Characteristics of the Participants}

The results on socio-demographic characteristics of the surveyed vegetable farmers in Arusha district are as indicated in Table 2. The socio-demographic characteristics recorded were gender, age and level of education.

Most of the respondents in this study, (52 representing $74.3 \%$ of participants), were male aged from 25 to 65 years with a mean age of $42.3 \pm 13.6$ years. It was reported that pesticide application in Arusha is done by men. In cases where farmers are women, they hired men to apply pesticides. As a consequence and considering exposure through inhalation or skin, the risks of exposure to pesticides for men can be higher than in women. The gender distribution is congruent to that made previously in the Manyara basin in Tanzania by Nonga et al. (2011), who reported $75 \%$ of farmers being male with a mean age of $47 \pm 14$ years. In a similar work done in Muheza, Arumeru, Singida and Kongwa, it was found that $85 \%$ of all farmers involved in vegetable cultivation were men (Weinberger \& Msuya, 2004). Studies done in other developing countries also report similar results (Amera \& Abate, 2008; Banjo et al., 2010).

More than half (52.9\%) of the vegetable farmers in Arusha district had a formal education of up to primary level. About one-fourth of the respondents had no formal education, and less than a quarter had secondary and college education. Illiteracy of farmers has been linked to poor pesticide application practices by farmers in previous surveys (Mengistie, Mol \& Oosterveer, 2015; Nonga et al., 2011).

Table 2. Socio-demographic characteristics of vegetable farmers $(n=70)$

\begin{tabular}{lll}
\hline Variable & Category & Percentage (\%) \\
\hline Sex & Male & 74.3 \\
& Female & 25.7 \\
Age & $15-35$ & 37.1 \\
& $36-45$ & 21.4 \\
\multirow{2}{*}{ Level of education } & 46 and above & 41.5 \\
& No formal education & 25.7 \\
& Primary school & 52.9 \\
& Secondary and higher level & 21.4 \\
\hline
\end{tabular}

\subsection{Pesticide Residue Contents in Ready-to-eat Vegetables}

Ready-to-eat vegetable samples were available from 70 out of the 76 farmers as six farmers were not willing to provide samples. The seventy (70) ready-to-eat vegetable samples were analyzed for pesticide residues. They included 31 African nightshade (44.3\%), 15 kale (21.4\%), 10 cabbage (14.3\%), three spinach (4.3\%), two Ethiopian mustard (2.9\%), one Chinese cabbage (1.4\%), two Amaranthus spp. (2.9\%) and six vegetables prepared with combinations of nightshade with kale (4.3\%), nightshade with kale and spinach (1.4\%), nightshade with Ethiopian mustard (1.4\%), or kale with spinach (1.4\%). Overall, $40 \%$ of all the 70 samples contained detectable levels of pesticide residues. Individually, $60.0 \%$ of cabbage, $53.3 \%$ of kale, $35.5 \%$ of nightshade, $33.3 \%$ of spinach and $33.3 \%$ of the mixed vegetables contained pesticide residues. No pesticide was detected in Amaranthus spp, Chinese cabbage, and Ethiopian mustard.

Among the 70 samples, 58 (83\%) were obtained from respondents' own grown vegetables whereas the remaining $12(17 \%)$ samples were from vegetables purchased from outside homes as follows: three and two nightshade samples, respectively, from neighbours and market, two kale samples (one from market and the other from a neighbour), two Amaranthus spp. samples (both from neighbours), kale and nightshade and kale and 
spinach for two mixed vegetable samples from the market and a neighbour, respectively. All the cabbage samples were obtained from respondents' own grown vegetables. Of the 12 samples from market or neighbours only two (17\%) contained detectable levels of pesticide residues whereas among the 58 samples from farmers own farm vegetables, $26(45 \%)$ contained detectable levels of residues. The farmers who obtained their vegetables from their neighbours disclosed that they preferred neighbours' vegetables because were grown without pesticides. This might be the reason why pesticide residues were not detectable in vegetables obtained from neighbours, except one nightshade sample which contained permethrin. It is also possible that the market vegetables had taken longer time, from harvest to consumption, as compared to home-grown vegetables until residues were measured. The longer time could allow reduction of pesticide residues to undetectable levels. This is concurrent with the statement of European Food Safety Authority that depending on the point along the distribution chain where vegetables are obtained, pesticide residues may have declined to levels not detectable at the time of consumption (EFSA, 2012).

There are published reports of higher prevalence of pesticide residues in vegetables than found in the current study. For instance, in Chile, pesticide analysis was done in 118 leafy vegetable samples and it was found that $72 \%$ of spinach samples contained detectable levels of pesticide residues (Elgueta, Moyano, Sepulveda \& Quiroz, 2017). In Algeria, 120 vegetable samples were analyzed and pesticide residues, detected in $57.5 \%$ of the samples (Mebdoua, et al., 2017). Another study which analyzed pesticide residues in parsley, lettuce and spinach in Turkey found that all of the samples contained detectable levels for two or more pesticide residues, including dichlorvos which was quantified in every vegetable at a prevalence of $100 \%$ (Esturk, 2014). The detected pesticide residues in the current study were all above EU-MRL. Other studies also detected pesticide residues in vegetables at levels above MRL. For instance, the pesticide residues quantified by Esturk, 2014 were at levels above MRL in 28\%, 20\% and 40\% of parsley, lettuce and spinach, respectively. High prevalence of pesticide residues at levels above MRL in ready-to-eat vegetables reflects the indiscriminate use and misuse of pesticides as reported in the literature (Ngowi et al., 2007; Nonga et al, 2011) and observed in the current study.

On the other hand, two studies in India found the lower prevalence of pesticide residues compared to the levels found in the current study. In those studies, $10 \%$ of 50 vegetable samples from Karnataka and 34\% of 250 vegetable samples from the Andaman Islands contained detectable levels of pesticide residues of which all of the positive samples (10\%) from Karnataka and $15.3 \%$ contained pesticide residues above MRL (Pujeri, Pujar, Hiremath, Pujari \& Yadawe, 2015; Swarman \& Velmurugan, 2012).

The detected pesticide residues were insecticides in the groups of organophosphates and pyrethroids which were, in $31.4 \%$ and $17.1 \%$ of the analysed vegetable samples, respectively. Organophosphate pesticides detected (with their prevalence in brackets) were dimethoate $(14.3 \%)$, acephate $(12.9 \%)$, profenofos $(8.57 \%)$, malathion $(2.86 \%)$ and dichlorvos (2.86\%) and the pyrethroid pesticides were permethrin (17.1\%), cypermethrin $(1.43 \%)$ and lambda-cyhalothrin (1.43\%). Representative chromatograms of the detected pesticides are presented in Figure 1 and 2. Range and mean concentration of pesticide residues in the ready-to-eat vegetables are presented in Table 3.

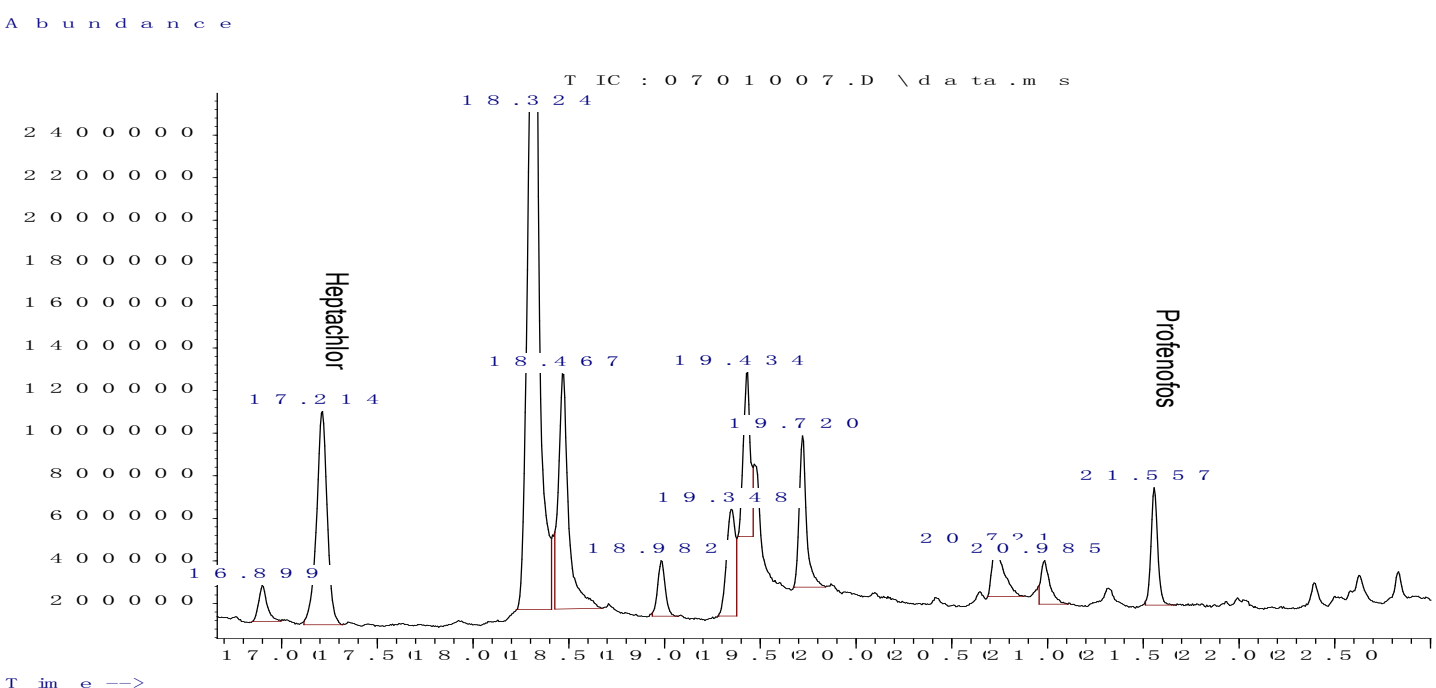

Figure 1. A chromatogram of Profenofos in kale 


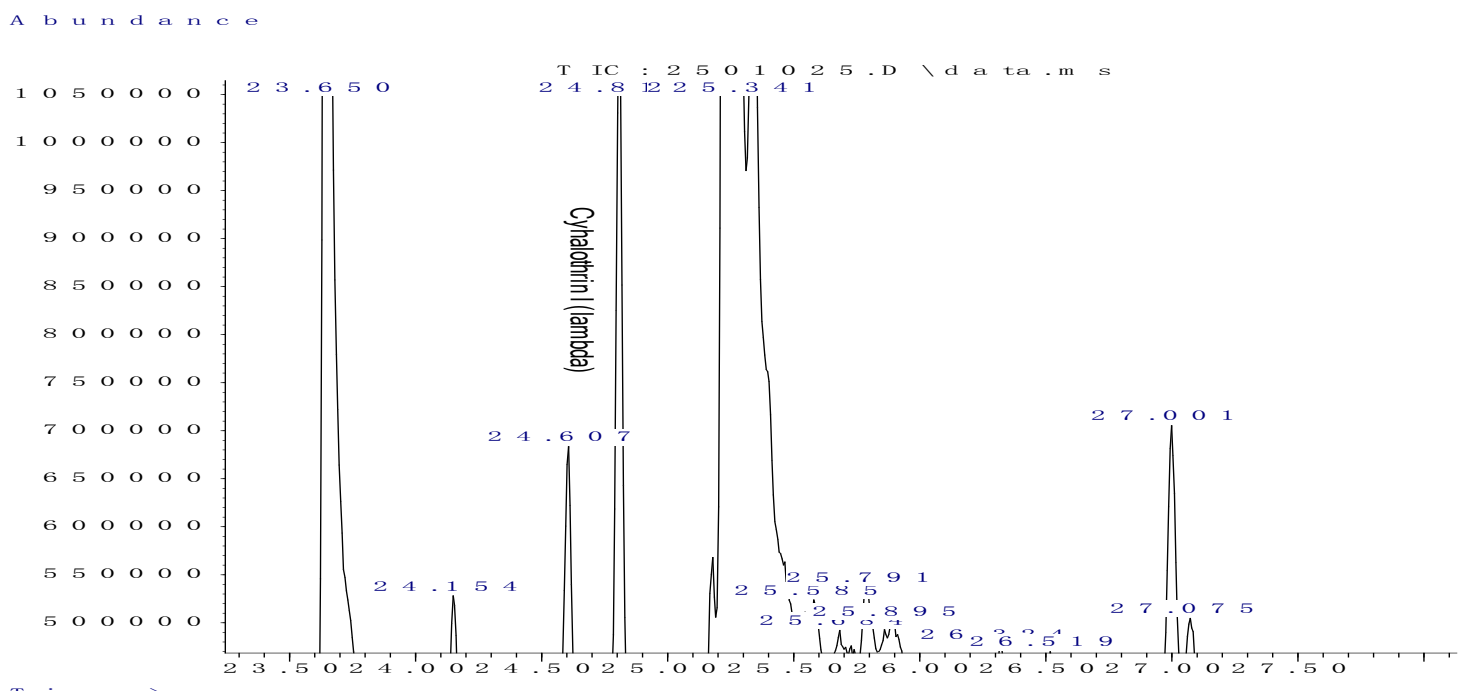

Figure 2. A chromatogram of Lambda cyhalothrin in kale

Organochlorine pesticides were not detected in the current study which is a good indication that there is a shift from the use of organochlorine pesticides to pyrethroid and organophosphorus pesticides and therefore a reduced risk of negative health effects associated with exposure to organochlorines. Organochlorines were detected in the studies done in Dar es Salaam (Mahugija, Khamis, \& Lugwisha, 2017; Ndengerio-Ndossi \& Cram, 2005). The organochlorine pesticides were found in foods as reported in 2005 despite the fact that they had been banned from use in agriculture in Tanzania since 1997 due to their long persistence in the environment and bioaccumulation properties (URT, 2005).

Table 3. Occurrence of pesticide residues in ready-to-eat vegetables $(n=70)$

\begin{tabular}{llrrr}
\hline $\begin{array}{l}\text { Pesticide group } \\
\text { prevalence, \%) }\end{array}$ & Pesticide & Prevalence (\%) & Range $\left(\mathrm{mg} \mathrm{kg}^{-1}\right)$ & $\mathrm{Mean} \pm \mathrm{SD}^{1}\left(\mathrm{mg} \mathrm{kg}^{-1}\right)$ \\
\hline Organophosphates (31.4\%) & Dimethoate & 14.3 & $2.88-15.4$ & $8.56 \pm 4.52$ \\
& Acephate & 12.9 & $0.33-12.4$ & $2.90 \pm 3.81$ \\
& Profenofos & 8.57 & $6.53-16.6$ & $8.44 \pm 3.98$ \\
& Dichlorvos & 2.86 & $8.60-33.0$ & $20.8 \pm 17.3$ \\
& Malathion & 2.86 & $4.63-6.31$ & $5.47 \pm 1.19$ \\
Pyrethroids (17.1\%) & Permethrin & 17.1 & $1.23-8.18$ & $2.95 \pm 1.92$ \\
& Lambda cyhalothrin & 1.43 & $<0.05-16.2$ & $16.2 \pm 0.05$ \\
& Cypermethrin & 1.43 & $<0.06-2.34$ & $2.34 \pm 0.06$ \\
\hline
\end{tabular}

${ }^{1}$ Standard deviation

Distribution, range and mean concentration of pesticides in individual vegetables are presented in Table 4 . The highest mean concentration for permethrin, dimethoate, and lambda-cyhalothrin $\left(3.44 \pm 0.93 \mathrm{mg} \mathrm{kg}^{-1}, 10.8 \pm 6.90\right.$ $\mathrm{mg} \mathrm{kg}{ }^{-1}$, and $16.2 \pm 0.05 \mathrm{mg} \mathrm{kg}^{-1}$ ), respectively, were found in kale samples whereas that of cypermethrin, acephate, malathion, and dichlorvos $\left(2.34 \pm 0.06 \mathrm{mg} \mathrm{kg}{ }^{-1}, 4.19 \pm 5.55 \mathrm{mg} \mathrm{kg}^{-1}, 5.47 \pm 1.19 \mathrm{mg} \mathrm{kg}^{-1}\right.$ and $33.0 \pm 0.01 \mathrm{mg} \mathrm{kg}^{-1}$ ), respectively, were found in nightshade. The highest mean concentration for profenofos $\left(16.4 \pm 0.01 \mathrm{mg} \mathrm{kg}^{-1}\right)$ was found in mixed vegetables.

The lowest mean concentrations of permethrin, cypermethrin and malathion $\left(1.7 \pm 0.05 \mathrm{mg} \mathrm{kg}^{-1}, 2.34 \pm 0.06 \mathrm{mg}\right.$ $\left.\mathrm{kg}^{-1}, 5.47 \pm 1.19 \mathrm{mg} \mathrm{kg}^{-1}\right)$, respectively, were found in nightshade. The lowest concentration for dimethoate $\left(6.48 \pm 2.68 \mathrm{mg} \mathrm{kg}^{-1}\right)$ was estimated in cabbage whereas that of acephate $\left(0.36 \mathrm{mg} \mathrm{kg}^{-1}\right)$, was found in mixed vegetables. The lowest mean concentration for dichlorvos and profenofos were quantified in kale $(8.60 \pm 0.01 \mathrm{mg}$ $\left.\mathrm{kg}^{-1}\right)$ and nightshade $\left(6.64 \pm 0.01 \mathrm{mg} \mathrm{kg}^{-1}\right)$, respectively. It should be noted that lambda cyhalothrin and cypermethrin were detected in one sample only. For the samples in which pesticide residues were detected, the concentrations were above the respective EU MRLs (Table 4). Quantification of pesticide residues in ready-to-eat-vegetables at levels higher than MRLs indicates poor adherence to good agricultural practices by vegetable farmers. 
Table 4. Variation of pesticide residues in individual types of ready-to-eat vegetables

\begin{tabular}{|c|c|c|c|c|c|c|c|c|c|}
\hline Vegetable (n) & Source (n) & Group & $\begin{array}{l}\text { Prevalence } \\
(\%)\end{array}$ & Pesticide & $\begin{array}{l}\text { MRL- } \\
(\mathrm{EU})\end{array}$ & $\begin{array}{l}\text { Range } \\
\left(\mathrm{mg} \mathrm{kg}^{-1}\right)\end{array}$ & $\begin{array}{l}\text { Mean } \pm \mathrm{SD}^{1} \\
\left(\mathrm{mg} \mathrm{kg}^{-1}\right)\end{array}$ & $f^{2}>\operatorname{LoD}(\%)$ & $f^{3}>\operatorname{MRL}(\%)$ \\
\hline \multirow[t]{4}{*}{ Cabbage(10) } & own farm(10) & Organophosphate & $6(60)$ & Dimethoate & 0.05 & $4.58-8.37$ & $6.48 \pm 2.68$ & (2) 20.0 & (2) 20.0 \\
\hline & & & & Profenofos & 0.01 & $<0.01-7.07$ & $7.07 \pm 0.01$ & (1) 10.0 & (1) 10.0 \\
\hline & & & & Acephate & 0.01 & $<0.01-1.97$ & $1.97 \pm 0.01$ & (1) 10.0 & (1) 10.0 \\
\hline & & Pyrethroids & & Permethrin & 0.05 & $1.44-3.91$ & $2.37 \pm 1.34$ & (3) 30.0 & (3) 30.0 \\
\hline \multirow[t]{7}{*}{ Kale(15) } & own farm(13) & Organophosphate & $8(53)$ & Dimethoate & 0.02 & $2.88-15.4$ & $10.8 \pm 6.90$ & (3) 20.0 & (3) 20.0 \\
\hline & & & & Acephate & 0.01 & $2.04-4.60$ & $3.32 \pm 1.81$ & (2) 13.3 & (2) 13.3 \\
\hline & & & & Profenofos & 0.01 & $<0.01-7.24$ & $7.24 \pm 0.01$ & (1)6.70 & (1) 6.67 \\
\hline & & & & Dichlorvos & 0.01 & $<0.01-8.60$ & $8.60 \pm 0.01$ & (1) 6.67 & (1) 6.67 \\
\hline & & Pyrethroids & & Permethrin & 0.05 & $2.62-4.45$ & $3.44 \pm 0.93$ & (3) 20.0 & (3) 20.0 \\
\hline & & & & Cyhalothrin & 0.05 & $<0.05-16.2$ & $16.2 \pm 0.05$ & (1)6.67 & (1) 6.67 \\
\hline & purchased (2) & Organophosphate & & Profenofos & 0.01 & $<0.01-6.53$ & $6.53 \pm 0.04$ & (1)6.67 & (1) 6.67 \\
\hline \multirow[t]{8}{*}{ Nightshade(31) } & own farm(26) & Organophosphate & $11(35.5)$ & Dimethoate & 0.02 & $4.25-12.0$ & $8.05 \pm 3.74$ & (5) 16.1 & (5) 16.1 \\
\hline & & & & Acephate & 0.01 & $0.33-12.4$ & $4.19 \pm 5.55$ & (4) 12.9 & (4) 12.9 \\
\hline & & & & Malathion & 0.02 & $4.63-6.31$ & $5.47 \pm 1.19$ & (2) 6.45 & (2) 6.45 \\
\hline & & & & Profenofos & 0.01 & $<0.01-6.64$ & $6.64 \pm 0.01$ & (1)3.22 & (1) 3.22 \\
\hline & & & & Dichlorvos & 0.01 & $<0.01-33.0$ & $33.0 \pm 0.01$ & (1)3.22 & (1)3.22 \\
\hline & & Pyrethroid & & Permethrin & 0.05 & $1.23-8.18$ & $3.40 \pm 3.20$ & (4) 12.9 & (4) 12.9 \\
\hline & purchased (5) & Pyrethroid & & cypermethrin & 0.05 & $<0.06-2.34$ & $2.34 \pm 0.06$ & (1)3.22 & (1)3.2 \\
\hline & & & & Permethrin & 0.05 & $<0.05-1.70$ & $1.70 \pm 0.05$ & (1)3.22 & (1) 3.2 \\
\hline \multirow[t]{3}{*}{ Mixed (6) } & own farm (4) & Organophosphate & $2(33.3)$ & Profenofos & 0.01 & $<0.01-16.4$ & $16.4 \pm 0.01$ & (1) 16.7 & (1) 16.7 \\
\hline & & & & Acephate & 0.01 & $0.30-0.42$ & $0.36 \pm 0.01$ & (2) 33.3 & (2) 33.3 \\
\hline & & Pyrethroid & & Permethrin & 0.05 & $<0.05-2.60$ & $2.60 \pm 0.05$ & (1) 16.7 & (1) 16.7 \\
\hline Spinach (3) & own farm (3) & Organophosphate & 1(33.3) & Profenofos & 0.01 & $<0.01-6.63$ & $6.67 \pm 0.01$ & (1) 33.3 & (1) 33.3 \\
\hline
\end{tabular}

${ }^{1}$ Standard deviation; ${ }^{2}$ detection frequency of the pesticide in the particular vegetable; ${ }^{3}$ Frequency of detected pesticides that were above MRL;

Source (MRLs): (European Comission, 2017)

Multiple pesticide residues were detected in $14.9 \%$ of the 70 samples. This prevalence is equivalent to $35.7 \%$ of the 28 samples which were positive for pesticide residues. Among the 31 nightshade and six mixed vegetable samples analyzed, $16.13 \%$ and $16.67 \%$, respectively, had multiple residues whereas among 15 kale samples $20 \%$ had multiple residues. Samples of cabbage had the lowest occurrence of multiple residues (one out of six (10\%)) (Table 5). Multiple occurrences of pesticide residues in vegetables have also been reported in literature: a study in Khazastan which analyzed 82 samples of tomato and cucumber found that $30 \%$ of the samples contained two to nine multiple pesticide residues in one sample (Lozowicka et al., 2015). Presence of multiple pesticide residues in one sample indicates that consumers are at higher risk of exposure and synergistic negative health effects of pesticides.

Table 5. Co-occurrence of multiple pesticide residues in ready-to-eat vegetables

\begin{tabular}{|c|c|c|}
\hline \multirow{2}{*}{$\begin{array}{l}\text { Vegetable } \\
\text { Kale }\end{array}$} & Pesticide residues combination & Prevalence (\%) \\
\hline & $\begin{array}{l}\text { Acephate, permethrin } \\
\text { Dimethoate, permethrin, cyhalothrin } \\
\text { Profenofos, dichlorvos, }\end{array}$ & 20.00 \\
\hline \multicolumn{3}{|c|}{ Overall prevalence in kale } \\
\hline Nightshade & $\begin{array}{l}\text { Dimethoate, dichlorvos, malathion } \\
\text { Acephate, dimethoate, permethrin } \\
\text { Acephate, dimethoate } \\
\text { Dimethoate, malathion } \\
\text { Permethrin, cypermethrin }\end{array}$ & 16.13 \\
\hline \multicolumn{3}{|l|}{$\begin{array}{l}\text { Overall prevalence in } \\
\text { nightshade }\end{array}$} \\
\hline $\begin{array}{l}\text { Nightshade with kale } \\
\text { and spinach mix }\end{array}$ & Acephate, profenofos, permethrin & 16.67 \\
\hline Cabbage & Dimethoate, permethrin & 10.00 \\
\hline
\end{tabular}

The quantified concentrations of most pesticide residues in the current study were higher than those found in other studies. Elgueta et al., 2017 quantified low pesticide residue concentrations in vegetables whereby 
lambda-cyhalothrin cypermethrin and permethrin were quantified at a range of $0.029-1.000 \mathrm{mg} \mathrm{kg}^{-1}, 0.00-1.61$ $\mathrm{mg} \mathrm{kg}$ and $0.00-1.45 \mathrm{mg} \mathrm{kg}^{-1}$, respectively, in chard, lettuce, and spinach. However, they quantified methamidophos (29.47 mg kg-1) and chlorpyrifos $\left(6.86 \mathrm{mg} \mathrm{kg}^{-1}\right)$ at higher concentrations than quantified in the current study. Also, a study in the Andaman Islands in India quantified profenofos, dimethoate and acephate in vegetables at a lower concentrations than that found in the current study whereby profenofos concentrations in the study done in the Andaman Islands ranged from $0.023-1.696 \mathrm{mg} \mathrm{kg}^{-1}$, acephate $0.083-0.509 \mathrm{mg} \mathrm{kg}^{-1}$ and dimethoate at $0.345 \mathrm{mg} \mathrm{kg}^{-1}$ (Swarman \& Velmurugan, 2012). However, a study in Egypt found a concentration of profenofos in green parsley $\left(7.2 \mathrm{mg} \mathrm{kg}^{-1}\right.$ ) (Gad-Alla, Lontfy, Shendy \& Ahmed, 2015) similar to that of the current study $\left(8.44 \mathrm{mg} \mathrm{kg}^{-1}\right)$. In Ghana, lower concentrations of $0.120-0.143 \mathrm{mg} \mathrm{kg}^{-1}$ as compared to $4.6-6.3 \mathrm{mg}$ $\mathrm{kg}^{-1}$ in the current study were found in vegetables. However, the prevalence of samples quantified with pesticide residues was higher in the Ghanian study than in this one (Darko \& Akoto, 2008). In Turkey, analysis of pesticide residues in 120 samples of parsley, lettuce and spinach found dichlorvos at concentrations ranging from $0.002-0.071 \mathrm{mg} \mathrm{kg}^{-1}$, levels that are lower than the $8.6-33.0 \mathrm{mg} \mathrm{kg}^{-1}$ levels found in this study. In Zambia, Sinyangwe et al. (2016) analysed dichlorvos residues in 14 lettuce, 15 cabbage and 9 rape samples and, by summing up the prevalence of the residues detected below and above MRL, found that $71 \%, 93 \%$ and $100 \%$ of lettuce, cabbage and rape plant samples, respectively, contained mean dichlorvos concentrations of $5.23 \mathrm{mg} \mathrm{kg}^{-1}$, $6.35 \mathrm{mgkg}^{-1}$ and $398.28 \mathrm{mg} \mathrm{kg}^{-1}$. The reported overall prevalence $(89 \%)$ is much higher than that obtained in the current study $(2.86 \%)$ for dichlorvos. Also, the concentration of dichlorvos residues in the rape plant reported in the same study is considerably higher than that found in the current study $\left(33 \mathrm{mg} \mathrm{kg}^{-1}\right)$.

WHO recommends classifying pesticides by acute risk to health whereby class Ia refers to pesticides that are extremely hazardous, class Ib are highly hazardous, class II are moderately hazardous, class III are slightly hazardous and class U are unlikely to cause acute health hazard (International Programme on Chemical Safety [IPCS], 2010). The pesticides residues found in the ready-to-eat vegetables analysed in this study are in class Ib, II and III. Most pesticides were found under Class II insecticides with exception of dichlorvos which is classified as class Ib and malathion classified as class III insecticides. These results indicate that vegetable farmers are shifting from using more to less hazardous pesticides and therefore exposed to reduced health effects. The class $\mathrm{Ib}$ pesticides are registered under restriction and therefore less accessible to vegetable farmers.

\subsubsection{Presence of Unauthorized Pesticides in Ready-to-Eat Vegetables}

In Tanzania, dichlorvos is restricted for the control of the larger grain borer in maize grain storage facilities. Pesticides registered for restricted use are those that are highly hazardous and intended for specific use or are technical materials for formulation purposes and must be used by specifically trained personnel or under close supervision of specifically trained personnel (URT, 2011). Dichlorvos, although less frequently detected (2.86\%) as compared to other organophosphate pesticides, was detected at the highest mean concentration of $20.8 \mathrm{mg} \mathrm{kg}^{-1}$ with a range of $8.6-33.0 \mathrm{mg} \mathrm{kg}^{-1}$ (Table 4). Detection of dichlorvos in ready-to-eat vegetables indicates misuse of pesticides. It is recommended to provide continuous training to vegetable farmers on pesticide application, and undertake regular monitoring of pesticide residues in vegetables to ensure that restricted pesticides such as dichlorvos are not inappropriately used and to control pesticide residues (in general) to acceptable levels in vegetables.

\subsection{Risk of Exposure above Acceptable Daily Intakes}

\subsubsection{Type, Frequency and Quantity of Consumed Vegetables}

The vegetable consumers in Arusha district consume vegetables as side dishes to main dishes that include stiff porridge, rice and banana. Among the mainly consumed leafy vegetables, African nightshade was the one most consumed. It was consumed by $43 \%$ of the respondents. For the vegetables used as a minor ingredient in the recipe, onions and tomatoes were consumed by most respondents (76.3 and 70.4, respectively). The average daily vegetable consumption at the time of the survey was $119 \mathrm{~g}$ per person. The consumption rates ranged from $14-302$ g per person per day. In Sub Saharan Africa, per capita daily vegetable consumptions ranging from $13 \mathrm{~g}$ (Malawi), through $70 \mathrm{~g}$ (Ethiopia) to $84 \mathrm{~g}$ (Guinea) and higher quantities ranging from $126 \mathrm{~g}$ (Rwanda) through $137 \mathrm{~g}$ (Ghana) and $142 \mathrm{~g}$ (Uganda) to $242 \mathrm{~g}$ (in Kenya) are reported (Minot and Smith, 2004 ). Note that the values in the review work were reported consumption per year but were converted into consumption per day in the current work to enable comparison. With the exemption of Kenya, average consumption of vegetables in developing countries is a half of the recommended amount of $200 \mathrm{~g}$ per person per day (Smith \& Eyzaguirre, 2007). It is recommended to consume at least $200 \mathrm{~g}$ of vegetables per day (Agudo \& Joint FAO, 2005; Keding, Weinberger, Swai, \& Mndiga, 2007). When considering this recommendation, only $18.6 \%$ of vegetable farmers in the Arusha district met the required daily vegetable consumption. If the farmers in Arusha consumed 
vegetables at the recommended intake of $200 \mathrm{~g}$ per person per day the risk of unacceptable pesticide intakes would increase considerably. Assuming a vegetable farmer with a body weight of $67 \mathrm{~kg}$ (the average body weight of farmers in Arusha district), consumes $200 \mathrm{~g}$ of vegetables, every day, containing pesticides at the mean concentrations determined in this study, mean exposures in $\mathrm{m} \mathrm{kg}^{-1}$ bwd $\mathrm{dor}^{-1}$ fhis farmer, with the pesticide in bracket, would be 0.0036 (dimethoate), 0.0018 (dichlorvos), 0.0022 (profenofos) and 0.0011 (acephate), 0.0005 (malathion) for organophosphate pesticides. For pyrethroids, the mean exposures would be 0.0011 (permethrin), 0.0001 (cypermethrin) and 0.007 for lambda-cyhalothrin. These would lead to unacceptable hazard quotients of 1.829 for dimethoate, and a hazard index of 2.385 for organophosphates. The hazard index for organophosphates is more than twofold the hazard index of 1.19 determined in this study with the normal vegetable consumption pattern. This indicates that promotion for increased vegetable consumption should go hand in hand with training and awareness raising to vegetable farmers on the appropriate use of pesticides and continuous monitoring and control of pesticide residues in vegetables.

\subsubsection{Risk of Chronic Pesticide Exposure}

Overall assessment of chronic exposure to pesticide residues through vegetable consumption indicates potential health risks to vegetable farmers. Among the 70 farmers that participated in this study, $18.6 \%$ were at potential health risks of unacceptable exposure to pesticide residues. Exposure levels and hazard indices of organophosphate and pyrethroid pesticides to vegetable farmers in Arusha district are presented in Tables 6a and $\mathrm{b}$ and $7 \mathrm{a}$ and $\mathrm{b}$, respectively.

The vegetable farmers were at higher health risk of unacceptable exposure of organophosphate pesticides. The hazard quotient of 7.5 was determined for dimethoate when considering positive detects only (Table 6a), and even after including non-detects assigned with the respective half limit of detection $(0.5$ LOD) in the mean exposure estimation was still above one (1.044) (Table 6b). The mean exposure level for this chemical was 0.015 $\mathrm{mg} \mathrm{kg}^{-1} \mathrm{bwd}^{-1}$ when considering positive detects only, and 0.0021 when $0.5 \mathrm{LOD}$ of this residue was included in the exposure estimation. Both values were above the ADI of dimethoate $\left(0.002 \mathrm{mg} \mathrm{kg}^{-1} \mathrm{bwd}^{-1}\right)$. The HQ of dimethoate was above one for kale (2.57 and 12.8 with and without 0.5 LOD included in the exposure estimation, respectively) whereas in cabbage it was 0.928 and 4.75 with and without the 0.5 LOD included in the estimation, respectively. Mean exposure for dichlorvos was $0.011 \mathrm{mg} \mathrm{kg}^{-1} \mathrm{bwd}^{-1}$ which was also above its corresponding ADI $\left(0.004 \mathrm{mg} \mathrm{kg}^{-1} \mathrm{bwd}^{-1}\right)$ yielding HQ of 2.75. After including 0.5 LOD in the exposure estimation for this residue, the mean exposure was reduced to 0.0003 and $\mathrm{HQ}$ of 0.075 was estimated, indicating a minimum potential health risk.

Mean exposure for other organophosphate (acephate, profenofos, and malathion) and pyrethroid (permethrin, cypermethrin, and lambda cyhalothrin) pesticide residues quantified in this study were below one in both scenarios indicating a minimum health risk. These results indicate that vegetable farmers in Arusha district are at risk of intolerable health effects associated with exposure to organophosphate pesticides and that the risk is mainly contributed to by intake of dimethoate through consumption of kale. Risk of cumulative exposures to the organophosphate pesticide residues is above one even after including the 0.5 LOD of the non-detects in the exposure estimation as shown by the Hazard index (HI) of 11 for positives only (Table 6a) and 1.19 after including the 0.5 LOD of the respective residues in the exposure (Table 8). The HI for pyrethroid pesticide residues was found to be below one in both scenarios $(0.029$ and 0.9 with and without the 0.5 LOD, included in the estimation, respectively) (Table $7 \mathrm{a}$ and $7 \mathrm{~b}$ ). These results show that the risk of exposure to the pesticide residues is overestimated when values for non-detects are not included in estimation of the risk. However, even after including these values it shows that there remains a risk of intolerable health effects and the risk is aggravated through multiple exposures to the organophosphate pesticide residues.

A study in Egypt reports cumulative hazard indices for organophosphates higher than those of pyrethroids but both of them below one (Gad-Alla et al., 2015; Thabet, Shendy, \& Gadalla, 2016). Usually, in Arusha district, vegetables are prepared for consumption for the entire family including children and pregnant women who are reported to be more vulnerable to health risks associated with exposure to pesticide residues than other groups of the population (FAO/WHO, 2009). Exposure to organophosphate pesticides during pregnancy has been linked with autism spectrum disorders (ASD) characterized by problems in socio-communication and restricted repetitive behaviours and pregnancy miscarriage. Children are more adversely exposed to the pesticide residues due to their small body size and therefore might be at a higher risk than estimated in this study for adults (Arbuckle, \& Lin, 2001; Eskenazi et al., 2004; Bouchard, et al., 2011). Furthermore, dietary exposure to pesticides is not limited to vegetables. The farmers may also be exposed to pesticides from other food types, water and air. 
Table 6a. Risk of dietary pesticides exposures above ADIs for organophosphate (positives only)

\begin{tabular}{|c|c|c|c|c|c|c|}
\hline Pesticide (Prevalence ) & Code & Vegetable & $\begin{array}{l}\text { Concentration } \\
\left(\mathrm{mg} \mathrm{kg}^{-1}\right)\end{array}$ & $\begin{array}{l}\text { EDI } \\
\left(\mathrm{mg} \mathrm{kg} \mathrm{bw}^{-1} \mathrm{~d}^{-1}\right)\end{array}$ & $\begin{array}{l}\mathrm{ADI} \\
\left(\mathrm{mg} \mathrm{kg}^{-1} \mathrm{bw}\right)\end{array}$ & $\mathrm{HQ} / \mathrm{HI}$ \\
\hline \multirow[t]{14}{*}{ Dimethoate (14.3\%) } & B26 & Nightshade & 4.25 & 0.011 & 0.002 & 5.500 \\
\hline & B41 & Nightshade & 12.0 & 0.013 & 0.002 & 6.500 \\
\hline & B1 & Nightshade & 11.7 & 0.005 & 0.002 & 2.500 \\
\hline & B74 & Nightshade & 7.75 & 0.016 & 0.002 & 8.000 \\
\hline & B4 & Nightshade & 4.54 & 0.005 & 0.002 & 2.500 \\
\hline & & Nightshade (average) & & 0.010 & & 5.000 \\
\hline & B71 & Kale & 15.4 & 0.052 & 0.002 & 26.00 \\
\hline & B36 & Kale & 14.1 & 0.023 & 0.002 & 11.50 \\
\hline & B5 & Kale & 2.88 & 0.002 & 0.002 & 1.000 \\
\hline & & Kale (average) & & 0.026 & & 12.80 \\
\hline & B62 & Cabbage & 4.58 & 0.003 & 0.002 & 1.500 \\
\hline & B6 & Cabbage & 8.37 & 0.016 & 0.002 & 8.000 \\
\hline & & Cabbage (average) & & 0.010 & & 4.750 \\
\hline & & & & 0.015 & & 7.500 \\
\hline \multirow[t]{3}{*}{ Dichlorvos $(2.86 \%)$} & B73 & Kale & 8.60 & 0.007 & 0.004 & 1.750 \\
\hline & B1 & Nightshade & 33.0 & 0.014 & 0.004 & 3.500 \\
\hline & & & & 0.011 & & 2.750 \\
\hline \multirow[t]{12}{*}{ Acephate (12.9\%) } & B15 & Spinach, nightshade & 0.30 & 0.001 & 0.030 & 0.033 \\
\hline & B33 & Kale, nightshade & 0.42 & 0.001 & 0.030 & 0.033 \\
\hline & B54 & Nightshade & 12.4 & 0.012 & 0.030 & 0.400 \\
\hline & B34 & Nightshade & 2.03 & 0.002 & 0.030 & 0.067 \\
\hline & B41 & Nightshade & 1.97 & 0.002 & 0.030 & 0.067 \\
\hline & B74 & Nightshade & 0.33 & 0.001 & 0.030 & 0.033 \\
\hline & & Nightshade (average) & & 0.004 & & 0.140 \\
\hline & B39 & Kale & 4.60 & 0.003 & 0.030 & 0.100 \\
\hline & B44 & Kale & 2.04 & 0.005 & 0.030 & 0.167 \\
\hline & & Kale (average) & & 0.004 & & 0.130 \\
\hline & B49 & Cabbage & 1.97 & 0.005 & 0.030 & 0.167 \\
\hline & & & & 0.004 & & 0.130 \\
\hline \multirow[t]{3}{*}{ Malathion (2.8\%) } & B1 & Nightshade & 6.31 & 0.000 & 0.300 & 0.001 \\
\hline & B4 & Nightshade & 4.63 & 0.005 & 0.300 & 0.017 \\
\hline & & Nightshade (average) & & 0.003 & & 0.009 \\
\hline \multirow[t]{9}{*}{ Profenofos $(8.6 \%)$} & B15 & Spinach, nightshade & 16.6 & 0.069 & 0.03 & 2.300 \\
\hline & B51 & Nightshade & 6.64 & 0.011 & 0.03 & 0.367 \\
\hline & B46 & Kale & 6.53 & 0.015 & 0.03 & 0.500 \\
\hline & B73 & Kale & 7.24 & 0.004 & 0.03 & 0.133 \\
\hline & & Kale (average) & & 0.010 & & 0.320 \\
\hline & B61 & Cabbage & 7.07 & 0.001 & 0.03 & 0.033 \\
\hline & 100 & Spinach & 6.63 & 0.015 & 0.03 & 0.500 \\
\hline & & & & 0.019 & & 0.630 \\
\hline & & & & & & $11.00^{*}$ \\
\hline
\end{tabular}

Note: ${ }^{1} \mathrm{mg} \mathrm{kgbw}^{-1} \mathrm{~d}^{-1}$ is $\mathrm{mg}$ per kg body weight per day; Source (ADI): (FAO \& WHO, 2015); The bolded values in the column of EDI are the mean exposure values for the particular pesticide in the vegetables; The bolded values in the HQ/HI column are the HQ values for particular pesticide in the vegetables *The HI for the organophosphates

Table 6b. Risk of dietary pesticides exposures above ADIs for organophosphate (including non-detects assigned with 0.5 LOD); EDIs in ( $\left.\mathrm{mg} \mathrm{kg} \mathrm{bw}^{-1} \mathrm{~d}^{-1}\right)$

\begin{tabular}{llllllll}
\hline $\mathrm{n}$ & Vegetable & Acephate & \multicolumn{3}{c}{ Dimethoate } & Profenofos \\
\hline & & Mean EDI & HQ & Mean EDI & HQ & Mean EDI & HQ \\
\hline 31 & African nightshade & 0.001 & 0.018 & 0.002 & 0.813 & 0.000 & 0.011 \\
15 & Kale & 0.001 & 0.018 & 0.005 & 2.570 & 0.001 & 0.046 \\
10 & Cabbage & 0.000 & 0.012 & 0.002 & 0.928 & 0.000 & 0.005 \\
3 & Spinach & 0.000 & 0.000 & 0.000 & 0.002 & 0.005 & 0.166 \\
2 & Ethiopian mustard & 0.000 & 0.000 & 0.000 & 0.003 & 0.000 & 0.000 \\
2 & Amaranthus spp & 0.000 & 0.000 & 0.000 & 0.001 & 0.000 & 0.000 \\
1 & Chinese & 0.000 & 0.000 & 0.000 & 0.005 & 0.000 & 0.000 \\
6 & Mixed vegetables & 0.000 & 0.011 & 0.000 & 0.002 & 0.011 & 0.382 \\
\hline
\end{tabular}


Table $6 \mathrm{~b}$. Risk of dietary pesticides exposures above ADIs for organophosphate (including non-detects assigned with $0.5 \mathrm{LOD})$; EDIs in $\left(\mathrm{mg} \mathrm{kg} \mathrm{bw}^{-1} \mathrm{~d}^{-1}\right)^{1}$ cont...

\begin{tabular}{llllll}
\hline $\mathrm{n}$ & Vegetable & Dichlorvos & \multicolumn{3}{c}{ Malathion } \\
\hline & & Mean EDI & $\mathrm{HQ}$ & Mean EDI & $\mathrm{HQ}$ \\
\hline 31 & African nightshade & 0.000 & 0.112 & 0.000 & 0.001 \\
15 & Kale & 0.001 & 0.116 & 0.000 & 0.000 \\
10 & Cabbage & 0.000 & 0.001 & 0.000 & 0.000 \\
3 & Spinach & 0.000 & 0.001 & 0.000 & 0.000 \\
2 & Ethiopian mustard & 0.000 & 0.001 & 0.000 & 0.000 \\
2 & Amaranthus spp & 0.000 & 0.001 & 0.000 & 0.000 \\
1 & Chinese & 0.000 & 0.002 & 0.000 & 0.000 \\
6 & Mixed vegetables & 0.000 & 0.001 & 0.000 & 0.000 \\
\hline
\end{tabular}

Table 7a. Risk of dietary pyrethroid pesticide exposures below ADIs (positives only)

\begin{tabular}{lllllll}
\hline Pesticide (Prevalence) & Code & Vegetable & $\begin{array}{l}\text { Concentration } \\
\mathrm{mg} \mathrm{kg}^{-1}\end{array}$ & $\begin{array}{l}\text { EDI } \\
\mathrm{mg} \mathrm{kgbw}^{-1} \mathrm{~d}^{-1}\end{array}$ & $\begin{array}{l}\text { ADI } \\
\mathrm{mg} \mathrm{kgbw}^{-1} \mathrm{~d}^{-1}\end{array}$ & HQ/HI \\
\hline Lambda cyhalothrin (1.4\%) & B5 & Kale & 16.2 & $\mathbf{0 . 0 1 2}$ & 0.02 & $\mathbf{0 . 6 0 0}$ \\
Cypermethrin (1.4\%) & B10 & Nightshade & 2.34 & $\mathbf{0 . 0 0 3}$ & 0.02 & $\mathbf{0 . 1 5 0}$ \\
Permethrin (17.1\%) & B15 & Spinach, nightshade & 2.60 & 0.011 & 0.05 & 0.220 \\
& B4 & Nightshade & 2.10 & 0.002 & 0.05 & 0.040 \\
& B10 & Nightshade & 1.70 & 0.002 & 0.05 & 0.040 \\
& B29 & Nightshade & 2.17 & 0.002 & 0.05 & 0.040 \\
& B28 & Nightshade & 1.23 & 0.002 & 0.05 & 0.040 \\
B41 & Nightshade & 8.18 & 0.009 & 0.05 & 0.180 \\
& B11 & Cabbage & 3.91 & 0.003 & & 0.068 \\
& B62 & Cabbage & 1.76 & 0.013 & 0.05 & 0.260 \\
& B3 & Cabbage & 1.45 & 0.002 & 0.05 & 0.020 \\
& B45 & Kabbage (average) & & 0.005 & 0.05 & 0.040 \\
& Kale & Kale & 3.45 & 0.010 & 0.05 & 0.110 \\
& B44 & Kale & 2.62 & 0.002 & 0.05 & 0.200 \\
& Kale (average) & & 0.007 & 0.05 & 0.140 \\
& & & 0.006 & & 0.130 \\
& & & 0.005 & & $\mathbf{0 . 1 0 0}$ \\
& & & & & $0.900^{*}$ \\
\hline
\end{tabular}

Note: ${ }^{1} \mathrm{mg} \mathrm{kgbw}^{-1} \mathrm{~d}^{-1}$ is $\mathrm{mg}$ per kg body weight per day; Source (ADI): (FAO/WHO, 2015); The bolded values in the column of EDI are the mean exposure values for the particular pesticide in the vegetables; ${ }^{*}$ The $\mathrm{HI}$ for the pyrethroids

Table 7b. Risk of dietary pesticide exposures below ADIs for pyrethroids (including non-detects assigned with $0.5 \mathrm{LOD})$; EDIs in $\left(\mathrm{mg} \mathrm{kg} \mathrm{bw}^{-1} \mathrm{~d}^{-1}\right)$

\begin{tabular}{llllllll}
\hline $\mathrm{n}$ & Vegetable & Permethrin & \multicolumn{3}{c}{ Cypermethrin } & \multicolumn{2}{c}{ Cyhalothrin } \\
\hline & & Mean EDI & HQ & Mean EDI & HQ & Mean EDI & HQ \\
\hline 31 & African nightshade & 0.001 & 0.011 & 0.000 & 0.005 & 0.000 & 0.000 \\
15 & Kale & 0.001 & 0.026 & 0.000 & 0.000 & 0.001 & 0.041 \\
10 & Cabbage & 0.002 & 0.031 & 0.000 & 0.000 & 0.000 & 0.000 \\
3 & Spinach & 0.000 & 0.000 & 0.000 & 0.000 & 0.000 & 0.000 \\
2 & Ethiopian mustard & 0.000 & 0.000 & 0.000 & 0.000 & 0.000 & 0.000 \\
2 & Amaranthus spp & 0.000 & 0.000 & 0.000 & 0.000 & 0.000 & 0.000 \\
1 & Chinese & 0.000 & 0.000 & 0.000 & 0.000 & 0.000 & 0.000 \\
6 & Mixed vegetables & 0.000 & 0.036 & 0.000 & 0.000 & 0.000 & 0.000 \\
\hline
\end{tabular}


Table 8. Average estimated daily intakes and hazard quotients of pesticide residues in vegetables

\begin{tabular}{llccc}
\hline Pesticide group & Pesticide residue & EDIs & HQ & HI \\
\hline Organophosphates & Dimethoate & 0.002 & 1.044 & 1.190 \\
& Acephate & 0.000 & 0.014 & \\
& Profenofos & 0.002 & 0.055 & \\
& Dichlorvos & 0.000 & 0.075 & \\
Pyrethroids & Malathion & 0.000 & 0.000 & \\
& Permethrin & 0.001 & 0.018 & 0.029 \\
& Cypermethrin & 0.000 & 0.002 & \\
& Cyhalothrin & 0.000 & 0.009 & \\
\hline
\end{tabular}

\subsection{Association of Pesticide Exposure and Application Practices}

Sources of vegetable for household consumption, knowledge and awareness on pesticide use, vegetable cropping systems and lack of advice from agricultural extension officers, pesticide application rates and adherence to pre-harvest interval were assessed in this study in order to establish their association with exposures to pesticide residues through vegetable consumption.

\subsubsection{Source of Vegetables}

Among the 70 vegetable farmers interviewed only 12 (17\%) reported to obtain their vegetables from market or neighbours as discussed in the previous section of pesticide residues in ready-to-eat vegetables. This finding indicates that most of the vegetable farmers consume what they produce. The farmers who bought vegetables reported that they usually do so while waiting for the pre-harvest interval to elapse after they have sprayed their own vegetables or prefer a different type of vegetable than what they have on their farm. It was revealed in this study that the odds of exposure to pesticide residues were 4.062 higher for farmers who consume own grown vegetable than for those who bought vegetables. However, the association was not statistically significant.

Results of pesticide exposure for vegetable farmers who reported to obtain the vegetable samples from their own farms $(\mathrm{n}=58)$ were used in the logistic regression analysis in order to clearly associate the practices and exposure levels. Results showing the association between exposure to pesticide residues and knowledge or application practices for pesticides are presented in Table 7.

\subsubsection{Knowledge and Awareness of Pesticide Application}

Knowledge and awareness of pesticide application are important for appropriate pesticide application and handling. Among the 58 vegetable farmers interviewed, only 20 (34.5\%) had attended some form of training on pesticide application. Among those 38 out of 58 who had no training, $52.6 \%$ were exposed to pesticide residues. Linear regression analysis shows that there is a significant association $(P=0.043)$ between lack of training on pesticide application and exposure to pesticide residues. The adjusted odds of exposure to pesticide residues are 3.73 times higher for the vegetable farmers who had no training than for those who had undertaken training on pesticide application.

It was reported that $81 \%$ (47) of the farmers had a low level of education (only up to primary level) and the others (19\%) had a higher level of education (secondary to university). A similar level of literacy is reported in other developing countries. In Nigeria, $96.2 \%$ of farmers had a low level of education (only up to primary level). The odds of exposure to pesticide residues for the farmers with a low level of education were 1.745 higher than for those who had a higher level of education but the results were not statistically significant $(p=0.634)$. These results suggest that continuous training and awareness raising among vegetable farmers on pesticide application regardless of their level of education can significantly reduce dietary exposure to the pesticide. The training should include provision of knowledge on health and environmental effects associated with indiscriminate use of pesticides and provide other options for pest and disease control so that farmers can willingly shift from relying on the indiscriminate use of synthetic pesticides to safer pest management methods such as the integrated pest management (IPM) approach. This approach combines various means of pest and disease control including the use of cultural and mechanical means, biological control such as introduction of beneficial insects and mites and minimum use of IPM compatible pesticides (Dijkxhoorn, Bremmer, \& Kerklaan, 2013; Lahr, Buij, Katagira, \& Valk, 2016). The approach is currently applied in Europe, and in parts of East Africa, particularly in Kenya for farmers who grow vegetables for export and who apply this practice in order to meet the stringent requirements that vegetables are not allowed to contain pesticide residues above MRLs (Maredia, Dakouo, \& Mota-Sanchezs, 2003). 
Table 9. Association between dietary exposure to pesticide residues with knowledge and pesticide application practices

\begin{tabular}{|c|c|c|c|c|c|c|c|}
\hline+ & Farmers exposed $(\%)$ & $p$-value & $\mathrm{OR}^{1}$ & $\mathrm{CI}^{2}(95 \%)$ & $\mathrm{AOR}^{3}$ & $p$-value & $\mathrm{CI}(95 \%)$ \\
\hline $\begin{array}{l}\text { Primary or lower level } \\
\text { of education }(n=47)\end{array}$ & 23 & 0.634 & 1.745 & $0.176-17.261$ & & & \\
\hline Source of vegetables (own grown $n=58$ ) & 44.8 & 0.087 & 4.062 & $0.817-20.201$ & & & \\
\hline $\begin{array}{l}\text { Lack of a formal training on } \\
\text { pesticide application }(n=20)\end{array}$ & 34.5 & 0.133 & 2.317 & $0.822-8.179$ & $3.73^{*}$ & 0.043 & $1.04-13.363$ \\
\hline $\begin{array}{l}\text { Vegetables intercropped } \\
\text { with cabbage }(n=33)\end{array}$ & 51.5 & 0.961 & 1.889 & $0.652-5.476$ & & & \\
\hline $\begin{array}{l}\text { Lack of advice from } \\
\text { extension officer }(n=13)\end{array}$ & 15.4 & $\mathbf{0 . 0 3 1}$ & 6.768 & 1.188-38.57 & $6.56 * *$ & $\mathbf{0 . 0 3 1}$ & $1.187-36.291$ \\
\hline Prepare pesticide at over-dosage $(n=24)$ & 58.3 & 0.032 & 4.12 & 1.127-15.06 & 3.751 & 0.038 & 1.078-13.06 \\
\hline Non-adherence to $\mathrm{PHI}^{4}(\mathrm{n}=31)$ & 32.3 & 0.038 & 3.83 & $1.166-11.659$ & 3.223 & 0.057 & $0.964-10.768$ \\
\hline
\end{tabular}

${ }^{1}$ odd ratio, ${ }^{2}$ confidence interval; ${ }^{3}$ adjusted odd ratio; ${ }^{4}$ the time that lags between last pesticide spraying and harvest of the vegetables; ${ }^{*}$ odds ratio of exposure to the residues for lack of training after be

ing adjusted from influence of low level of education and lack of advice from extension officer; **adjusted odds ratio of exposure to the residues for lack of advice from extension officers after being adjusted for confounding influence of lack of adherence to PHI and over-dosage; the bolded values are for practices with significant association.

\subsubsection{Vegetable Cropping System}

During the field survey, it was observed that vegetables were grown in small farms (mostly $\leq 0.5$ acre) located close to the residential area of the respondents. Vegetables were either intercropped or in separate plots. Most of the farmers who grew cabbage and other types of vegetables claimed that they separated cabbage from other crops because the crop is more frequently sprayed with pesticides. Thus, they separated cabbage from the other vegetables in order to control pesticide cross-contamination. Among the 58 respondents who consumed vegetables from their own farm, 55.2\% (32) reported growing cabbage, of which $75 \%$ planted cabbage in a separate farm. Among those who intercropped cabbage with other vegetables, $62.5 \%$ were exposed to pesticide residues. However, there was no significant association between intercropping cabbage with other vegetables and exposure to pesticide residues $(p=0.961$, odds ratio $=3.769$ ).

Results of pesticide residue analysis in the vegetable samples show that pesticide residues were more frequently detected in cabbage samples than other vegetables. Of the cabbage samples, $60 \%$ contained pesticide residues higher than $53.3 \%$ of kale and $35.5 \%$ of nightshade (Table 4). However, the occurrence of multiple pesticide residues was higher in nightshade $18.75 \%$ and kale $10.5 \%$ than in cabbage (10\%), indicating that the farmers' claim is not valid. Literature reports that intercropping of cabbage with appropriate vegetables (referred to in the literature as companion crops) has potential for controlling pests in vegetables and thus minimising pesticide use. For instance, intercropping cabbage with alliums and tomato were found to significantly minimise pests in the field (Baidoo, 2012; Debra \& Misheck, 2014; Luchen, 2001).

\subsubsection{Lack of Advice from Agricultural Extension Officers}

The role of agricultural extension officers is to provide farmers with knowledge, information, experience, and technology which are important for improved productivity. In the current study, most of the vegetable farmers $(84.6 \% ; n=58)$ reported that they did not seek agricultural officer advice on pesticide application issues. Of those who did not rely on the officers' advice, $53.3 \%$ were exposed to pesticide residues. The result from the regression analysis indicates that there is a significant association between exposure to pesticide residues and lack of advice from agricultural extension officers $(p=0.031)$. The adjusted odds for exposure to pesticide residues are 6.56 higher in the farmers who did not rely on extension officers' advice than for those who did.

Literature reports that most of vegetable farmers do not rely on extension officers' advice in pesticide application issues (Issa \& Atala, 2012; Lekei et al., 2014; Ngowi et al., 2007). Each ward and two villages (Shiboro and Siwandeti) visited in the current study had at least one agricultural extension officer. Therefore, if agriculture extension services were well-equipped by the government and utilized by farmers, the risk of exposure to pesticide residues would be minimized.

\subsubsection{Over-dosage of Pesticides}

Appropriate pesticide preparation is crucial for controlling pesticide residues in vegetables. By comparing application rates for pesticides as indicated on labels of pesticides to the rates applied to vegetables, it was 
realized that $41.1 \%$ of the interviewed farmers prepared pesticides at over-dosage. Among those who prepared pesticides at over-dosage, $58.3 \%$ were exposed to pesticide residues. The adjusted odds ratio of exposure to the residues was found to be 3.751 higher in the farmers who prepared pesticides at over-dosage than for those who prepared pesticides accurately. The association was statistically significant at $p=0.038$. Pesticide dosage has been a great challenge in developing countries because most farmers dose inaccurately which results in excessive pesticide residues in vegetables (Adjrah et al., 2013; Banjo et al., 2010; Sheikh, Nizamani, Panhwar, \& Mirani, 2013).

During the field survey farmers reported measuring liquid pesticides with calibrated caps, most of them delivered together with the pesticide package. However, in the case of powdery pesticides such as Linkmil 72WP, Ebony $72 \mathrm{WP}$, and Ivory $72 \mathrm{WP}$, tablespoons were used as measurement tools. This is a bad practice because powdery pesticides should be weighed in grams. Unpublished information from the Horticultural Research and Training Institute Tengeru, Arusha informed that the lack of appropriate measures such as weighing scales for powdery pesticides is a common challenge. Extension officers further have attempted to calibrate commonly used equivalent tools at the farm level, such as spoons, but it is still a challenge because new pesticides which are lighter or heavier than those previously used for calibration, are entering the market. A similar challenge is reported in Ethiopia where farmers use non-calibrated measuring tools (Mengistie, Mol and Oosterveer, 2015). Pesticide formulators and extension officers should find means for farmers to be able to measure an accurate quantity of pesticide. This will minimize the risk of exposure to pesticide residues associated with the inappropriate measurement of pesticide quantities.

\subsubsection{Adherence to Pre-harvest Interval (PHI)}

The time that lags between the last pesticide spraying and harvest of the vegetables is important to ensure reduction levels of the applied pesticides to at least the recommended maximum residual levels. Field surveys revealed that all vegetable farmers interviewed were aware of PHI. Among the 58 respondents, 31 (53.4\%) reported waiting for the recommended PHI whereas 27 (46.6\%) harvest earlier than the recommended intervals. Adherence to PHI was in concurrence with the effectiveness of pesticides. More than three quarters (87.1\%) of the farmers who reported that the pesticides applied were effective, could adhere to PHI. Among the farmers who reported to harvest vegetables before the recommended interval $(n=21), 59.3 \%$ were exposed to pesticide residues through vegetable consumption. The odds ratio of exposure to the residues was 3.83 times higher for the farmers who did not adhere to PHI and the result was statistically significant at $p=0.026$. However, after adjusting for confounding influences such as the lack of advice from extension officers, the results showed no significant association $(p=0.057)$ suggesting that the lack of advice from extension officers was the cause for non-adherence to PHI. It is therefore suggested that farmers should be advised on the importance of adherence to PHI so that safe vegetables are produced for their own consumption and for other consumers.

\section{Conclusion and Recommendations}

The findings of the present study indicate that $18.6 \%$ of vegetable farmers in Arusha district are at potential risk of exposure to organophosphate pesticide residues through vegetable consumption. The risk is due to high levels (above MRLs) of organophosphate pesticide residues that were detected in almost one-third of vegetable samples. Dimethoate was the main contributor to the exposure to high levels of organophosphates with a hazard index above one. Other organophosphate pesticides detected were dichlorvos, acephate, profenofos, and malathion whose HQs were below one. Pyrethroids including permethrin, cypermethrin, and lambda-cyhalothrin were also detected having HQ and combined HI below one, indicating a minimum potential health risk. Our findings showed that lack of formal training on pesticide application, non-reliance on agricultural extension officers' advice and over-dosage of pesticides are the main factors for the observed potential risk of exposure to pesticide residues. Since vegetable farms were closer to the residential houses, there are possibilities that individuals, especially pregnant women and children, are at higher risk of exposure through other routes such as inhalation and skin contact. For that reason, we recommend that an exposure assessment for the general population be carried out using a more robust approach that includes other potential routes including consumption, inhalation and skin contact. The risk may be minimized by observing extension service advice, specifically by observing pre-harvest intervals for these pesticides and applying pesticides at an appropriate dosage.

\section{Conflict of interest}

The authors declare no conflict of interest 


\section{Acknowledgements}

The authors acknowledge the NIMR Muhimbili Centre and the Consortium Afrique One for their technical support on data analysis and manuscript preparation. Afrique One is funded by the Wellcome Trust (WT087535MA).The study was funded by the government of Tanzania through The Nelson Mandela African Institution of Science and Technology.

\section{References}

Adjrah, Y., Dovlo, A., Karou, S. D., Eklu-Gadegbeku, K., Agbonon, A., de Souza, C., \& Gbeassor, M. (2013). Survey of pesticide application on vegetables in the Littoral area of Togo. Annals of Agricultural and Environmental Medicine, 20(4), 715-720. Retrieved from https://www.ncbi.nlm.nih.gov/pubmed/24364441

Agenda. (2006). Pesticide and poverty: A case study on trade and utilization of pesticides in Tanzania: Implication to Stockpiling. Dar es Salaam.

Agudo, A., \& Joint FAO. (2005). Measuring intake of fruit and vegetables. World Health Organization, 40. http://doi.org/10.1017/CBO9781107415324.004

Amera, T., \& Abate, A. (2008). An assessment of the pesticide use, practice and hazards in the Ethiopian rift valley. Africa Stockpiles Program, 1-61. Retrieved from

http://www.thenrgroup.net/theme/PAN-ecotox/pdf/annex_6_ethiopia_mini-project_report.pdf

AOAC. (2007). AOAC Official Method 2007.01 Pesticide residues in foods by acetonitrile extraction and partitioning with magnesium sulfate applicable for the following pesticides in grapes, lettuces, and oranges: atrazine, azoxystrobin, bifenthrin, carbaryl. AOAC International. Retrieved from https://nucleus.iaea.org/fcris/methods/AOAC_2007_01.pdf

Arbuckle, Y., Lin, Z. and M. L. (2001). An exploratory analysis of the effect of pesticide exposure on the risk of spontaneous abortion in an Ontario farm population. Environmental Health Perspectives, 109(8), 851-857. Retrieved from https://pdfs.semanticscholar.org/19dc/3c9011a5f1cfbafcb2631724ced252366f77.pdf

Baidoo, P. K. (2012). Onion as a pest control intercrop in organic cabbage (Brassica oleracea) production system in Ghana. Sustainable Agriculture Research, 1(1), 36-41. http://doi.org/10.5539/sar.v1n1p36

Banjo, A. D., Aina, S. A., \& Rije, O. I. (2010). Farmers' knowledge and perception towards herbicides and pesticides usage in Fadama area of Okun-Owa, Ogun State of Nigeria. African Journal of Basic \& Applied Sciences, 2(56), 188-194.

Bouchard, M., Chevrier, J., Harley, K.G., Kogut, K., Vedar, M., Calderon, N., Trujillo, C., Johnson, C., Bradman, A., Barr, B. B., \& Eskenazi, B. (2011). Prenatal exposure to organophosphate pesticides and IQ in 7-year-old children. Environmental Health Perspectives, 119(8), 1189-1195. http://doi.org/10.1289/ehp.1003185

Campdelacreu, J. (2012). Parkinson's disease and Alzheimer's diseases: environmental risk factors. Neurologia, 29(9), 541-549. Retrieved from https://www.ncbi.nlm.nih.gov/pubmed/22703631

Charan, J., \& Biswas, T. (2013). How to calculate sample size for different study designs in medical research? Indian Journal of Psychlogical Medicine, 35(2), 121-126. http://doi.org/10.4103/0253-7176.116232

Darko, G., \& Akoto, O. (2008). Dietary intake of organophosphorus pesticide residues through vegetables from Kumasi, Ghana. Food and Chemical Toxicology, 46(12), 3703-3706.

http://doi.org/10.1016/j.fct.2008.09.049

Debra, K. R., \& Misheck, D. (2014). Onion (Allium cepa) and garlic (Allium sativum) as pest control intercrops in cabbage based intercrop systems in Zimbabwe, 7(2), 13-17. Retrieved from https://www.researchgate.net/publication/271255202

Dijkxhoorn, Y., Bremmer, J., \& Kerklaan, E. (2013). Towards Integrated Pest Management in East Africa. Wageningen. Retrieved from www.wageningenUR.nl/en/lei

EFSA. (2008). Opinion of the Scientific Panel on plant protection products and their residues to evaluate the suitability of existing methodologies and, if appropriate, the identification of new approaches to assess cumulative and synergistic risks from pesticides to human health with a view to set MRLs for those pesticides in theframe of Regulation (EC) 396/2005. EFSA Journal, 704, 1-84. http://doi.org/10.2903/j.efsa.2008.705

EFSA. (2012). Guidance on the use of probabilistic methodology for modelling dietary exposure to pesticide 
residues. EFSA Journal, 10(10), 1-95. http://doi.org/10.2903/j.efsa.2012.2839.

Elgueta, S., Moyano, S., Sepúlveda, P., \& Quiroz, C. (2017). Pesticide residues in leafy vegetables and human health risk assessment in North Central agricultural areas of Chile. Food Additives \& Contaminants: Part $B, 10(2), 105-112$. http://doi.org/10.1080/19393210.2017.1280540

Eskenazi, B., Harley, K., Bradman, A., Weltzien, E., Jewell, N. P., Barr, D. B., ... Holland, N. T. (2004). Association of in-utero organophosphate pesticide exposure and fetal growth and length of gestation in an agricultural population. Environmental Health Perspectives, 10, 1116-1124.

http://doi.org/10.1289/ehp.6789

Esturk, O. (2014). Pesticide residue analysis in parsley, lettuce and spinach by LC-MS / MS. Journal of Food Science and Technology, 51, 458-466. http://doi.org/10.1007/s13197-011-0531-9

European Comission. (2017). European Commission pesticides database. Retrieved April 13, 2015, from http://ec.europa.eu/food/plant/pesticides/eu-pesticides-database/public/?event=pesticide.residue.selection\& language $=\mathrm{EN}$

FAO/WHO. (1997). Guidelines for predicting dietary intake of pesticide residues. Switzerland. Retrieved from http://www.who.int/foodsafety/publications/chem/en/pesticide_en.pdf

FAO/WHO. (2005). Pesticide residues in food - 2004. Rome. Retrieved from http://www.fao.org/fileadmin/templates/agphome/documents/Pests_Pesticides/JMPR/Reports_1991-2006/r eport2004jmpr.pdf

FAO/WHO. (2009). Principles and methods for the risk assessment of chemicals in food: Dietary exposure assessment of chemicals in food. International Programme on Chemical Safety. Stuttgart.

FAO/WHO. (2015). Codex committee on pesticide residues Codex Alimentarius Commission, Joint FAO and WHO Food Standard Programme. Beijing, China.

Gad-Alla, S. A., Loutfy, N. M., Shendy, A. H., \& Ahmed, M. T. (2015). Hazard Index, a tool for a long term risk assessment of pesticide residues in some commodities, a pilot study. Regulatory Toxicology and Pharmacology. http://doi.org/10.1016/j.yrtph.2015.09.016

Hashmi, Imran, \& Dilshad, K. A. (2004). Adverse health effects of pesticide exposure in agricultural and industrial workers of developing country. In M. Stoytcheva (Ed.), Pesticides- The impacts of Pesticides exposure (pp. 155-178). Shanghai: In Tech. Retrieved from

http://www.intechopen.com/books/pesticides-the-impacts-of-pesticides-exposure/adverse-health-effects-of pesticides-exposure-in-agricultural-and-industrial-workers-of-developing-c

IPCS. (2010). The WHO recommended classification of pesticides by hazard and guidelines to classification. Geneva: WHO. Retrieved from http://www.who.int/ipcs/publications/pesticides_hazard_2009.pdf

Issa F.O., Atala T.K., A. J. G. and S. S. . (2012). Adoption of recommended agrochemical practices among crop farmers in Kaduna and Ondo States, Nigeria. Journal of Agricultural Extension, 18(2), 10-20. http://doi.org/http://dx.doi.org/10.4314.jae.v19i1.12

Kariathi, V., Kassim, N., \& Kimanya, M. (2016). Pesticide exposure from fresh tomatoes and its relationship with pesticide application practices in Meru district. Cogent Food \& Agriculture, 2(1), 1-12. http://doi.org/10.1080/23311932.2016.1196808

Keding, G., Weinberger, K., Swai, I., \& Mndiga, H. (2007). Diversity, traits and use of traditional vegetables in Tanzania. Technical bulletin (Vol. 40). Retrieved from http://libnts.avrdc.org.tw/scripts/minisa.dll/144/VAVLIB/VAVLIB_SDI_REPORT/SISN+9326?SESSIONS EARCH

Keifer C. (2008). Neurotoxicity of pesticides. Journal of Agromedicine, 12, 37-41. http://doi.org/10.1300/J096v12n01

Kimanya, M. E., de Meulenaer, B., Baert, K., Tiisekwa, B., van Camp, J., Samapundo, S., ... Kolsteren, P. (2009). Exposure of infants to fumonisins in maize-based complementary foods in rural Tanzania. Molecular Nutrition and Food Research, 53(5), 667-674. http://doi.org/10.1002/mnfr.200700488

Kofi, C., Akomeah, A., Akuamoa, F., Frimpong, S., \& Buah-kwofie, A. (2016). Dietary exposure to chlorinated pesticide residues in fruits and vegetables from Ghanaian markets. Journal of Food Composition and Analysis, 46, 103-113. http://doi.org/10.1016/j.jfca.2015.12.001 
Laffin, B., Chavez, M., \& Pine, M. (2010). The pyrethroid metabolites 3-phenoxybenzoic acid and 3-phenoxybenzyl alcohol do not exhibit estrogenic activity in the MCF-7 human breast carcinoma cell line or Sprague - Dawley rats, 267, 39-44. http://doi.org/10.1016/j.tox.2009.10.003

Lahr, J., Buij, R., Katagira, F., \& Valk, H. Van Der. (2016). Pesticides in the Southern Agricultural Growth Corridor of Tanzania ( SAGCOT ); A scoping study of current and future use, associated risks and identification of actions for risk mitigation. Wageningen. Retrieved from http://edepot.wur.nl/394164

Lekei, E. E., Ngowi, A. V, \& London, L. (2014). Farmers' knowledge, practices and injuries associated with pesticide exposure in rural farming villages in Tanzania. BMC Public Health, 14(1), 389. http://doi.org/10.1186/1471-2458-14-389

Lozowicka, B., Abzeitova, E., Sagitov, A., Kaczynski, P., Toleubayev, K., \& Li, A. (2015). Studies of pesticide residues in tomatoes and cucumbers from Kazakhstan and the associated health risks. Environmental Monitoring and Assessment, 187(10), 1-19. http://doi.org/10.1007/s10661-015-4818-6

Luchen, W. S. (2001). Effects of intercropping cabbage with Alliums and tomato, on the incidence of the diamondback moth, Plutella xylostella (L.). Lusaka: University of Zambia. Retrieved from http://dspace.unza.zm:8080/xmlui/bitstream/handle/123456789/1858/luchen00001.PDF?sequence=1

Mahugija, J. A. M., Khamis, F. A., \& Lugwisha, E. H. J. (2017). Determination of levels of organochlorine, organophosphorus, and pyrethroid pesticide residues in vegetables from markets in Dar es Salaam by GC-MS. International Journal of Analytical Chemistry, 2017, 1-9. http://doi.org/https://doi.org/10.1155/2017/4676724

Manyilizu, W. B., \& Mdegela, R. H. (2015). Self-reported health effects among short and long-term pesticide sprayers in Arusha, Northern Tanzania: A cross sectional study. Occupational Medicine \& Health Affairs, 3(6). http://doi.org/10.4172/2329-6879.1000223

Maredia, K. M., Dakouo, D., \& Mota-Sanchezs, S. (2003). Integrated pest management in the global arena. (D. Maredia, K.M., Dakouo, D. and Mota-Sanchez, Ed.)CABI (Vol. 1). Wallingford: CABI. http://doi.org/10.1017/CBO9781107415324.004

Mebdoua, S., Lazali, M., Ounane, S. M., \& Tellah, S. (2017). Evaluation of pesticide residues in fruits and vegetables from Algeria. Food Additives \& Contaminants: Part B, 10(2), 91-98. http://doi.org/10.1080/19393210.2016.1278047

Mengistie, B. T., Mol, A. P. J., \& Oosterveer, P. (2015). Pesticide use practices among smallholder vegetable farmers in Ethiopian Central Rift Valley. Environment, Development and Sustainability. http://doi.org/10.1007/s10668-015-9728-9

Ndengerio-Ndossi, J. P., \& Cram, G. (2005). Pesticide residues in table-ready foods in Tanzania. International Journal of Environmental Health Research, 15(2), 143-149. http://doi.org/10.1080/09603120500061922

Ngowi, Mbise, T. J., Ijani, A. S. M., London, L., \& Ajayi, O. C. (2007). Smallholder vegetable farmers in Northern Tanzania: Pesticides use practices, perceptions, cost and health effects. Crop Protection, 26(11), 1617-1624. http://doi.org/10.1016/j.cropro.2007.01.008

Nonga et al. (2011). Assessment of farming practices and uses of agrochemicals in Lake Manyara basin , Tanzania. Journal of Agricultural Research, 6(10), 2216-2230. http://doi.org/10.5897/AJAR11.271

Pujeri, U. S, Pujar, A. S., Hiremath, S. C., Pujari, K. G., \& Yadawe, M. S. (2015). Analysis of pesticide residues in vegetables in Vijayapur, Karnataka. World Journal Of Pharmacy And Pharmaceutical Sciences, 4(7), 1743-1750. Retrieved from https://www.researchgate.net/publication/280244475

Putter, H. De, \& Koesveld, M. J. Van. (2007). Overview of the vegetable sector in Tanzania. Netherlands. Retrieved from http://edepot.wur.nl/30946

Ruel, M.T. Minot, N. and S. L. (2004). Patterns and determinants of fruit and vegetable consumption in Sub Saharan Africa: Amulticountry comparison. In Joint FAO/WHO workshop on fruits and vegetables for health.

Sanchez-Santed, C. and H. (2015). Organophosphate pesticide exposure and neurodegradation. Cortex, 74, 417-426. http://doi.org/https://doi.org/10.1016/j.cortex.2015.10.003

SANCO. (2014). Guidance document on analytical quality control and validation procedures for pesticide residues analysis in food and feed. European commision. Retrieved from http://www.eurl-pesticides.eu/library/docs/allcrl/AqcGuidance_Sanco_2013_12571.pdf 
SCF. (2008). High value and fresh vegetables for local market sub sector analysis Tanzania: Executive summary. Dar es Salaam. Retrieved from http://www.tzdpg.or.tz/fileadmin/_migrated/content_uploads/Vegetables_-Executive_Summary_FFV_Stud ies_pdf_1_.pdf

Sheikh, S. A., Nizamani, S. M., Panhwar, A. A., \& Mirani, B. N. (2013). Monitoring of pesticide residues in vegetables collected from markets of Sindh Pakistan, 4(1), 41-45. Retrieved from http://oaji.net/articles/2014/27-1394777966.pdf

Sinyangwe, D.M., Mbewe, B. and Sijumbila, G. (2016). Determination of dichlorvos residue levels in vegetables sold in Lusaka, Zambia. Pan African Medical Journal, 8688, 1-7. http://doi.org/10.11604/pamj.2016.23.113.8211

Smith F.I and Eyzaguirre, P. (2007). African leafy vegetables: their role in the World Health Organization's global fruit and vegetable initiative. African Journal of Food, Agriculture and Nutritional Development, 7(3), 1-17.

Swarman and Velmurugan. (2012). Pesticide residues in vegetable samples from the Andaman Islands, India. Environmental Monitoring Assessment, 185, 6119-6127. http://doi.org/DOI 10.1007/s10661-012-3012-3

Thabet, W. M., Shendy, A. H., \& Gadalla, S. A. (2016). Chronic exposure of insecticide and fungicide as indicator of health impact in some commonly consumed leafy vegetables: Case study. Cogent Food \& Agriculture, 2. http://doi.org/10.1080/23311932.2016.1193926

Thatheyus, A. J., \& Gnana Selvam, A. D. (2013). Synthetic pyrethroids: Toxicity and biodegradation. Applied Ecology and Environmental Sciences, 1(3), 33-36. http://doi.org/10.12691/aees-1-3-2

Toft, G., Hagmar, L., Giwercman, A., \& Peter, J. (2004). Epidemiological evidence on reproductive effects of persistent organochlorines in humans, 19, 5-26. http://doi.org/10.1016/j.reprotox.2004.05.006

URT. (2005). National Implementation plan (NIP) for the Stockholm convention on persistent organic pollutants (PoPs) Vice president's office Division of Environment. Dar es Salaam.

URT. (2011). Orodha ya viuatilifu vilivyosajiliwa Tanzania Toleo la November, 2011 (Vol. 2505871). Arusha. Retrieved from http://www.tpri.or.tz/news/Pesticides_Gazette_2011.pdf

URT. (2012). The United Republic of Tanzania National sample census of agriculture 2007 / 2008 Volume Vs: Regional report: - Arusha Region The United Republic of Tanzania (Vol. V). Zanzibar. Retrieved from http://harvestchoice.org/sites/default/files/downloads/publications/Tanzania_2007-8_Vol_5b.pdf

USEPA. (2000). Assigning values to non-detected/non-quantified pesticide residues in human health food exposure. Office of Pesticide Programs, 8-11. Retrieved from https://archive.epa.gov/pesticides/trac/web/pdf/trac3b012.pdf

USEPA. (2005). Environmental Protection Agency. Guidelines for carcinogen risk assessment. Washington, DC. Retrieved from https://www3.epa.gov/airtoxics/cancer_guidelines_final_3-25-05.pdf

Weinberger, K., \& Msuya, J. (2004). Indigenous Vegetables in Tanzania: Significance and prospects. Technical Bulletin No.31: The World Vegetable Center. Shanhua: AVRDC. http://doi.org/10.1017/CBO9781107415324.004

Zyoud, S. H., Sawalha, A. F., Sweileh, W. M., Awang, R., Al-Khalil, S. I., Al-Jabi, S. W., \& Bsharat, N. M. (2010). Knowledge and practices of pesticide use among farm workers in the West Bank, Palestine: Safety implications. Environmental Health and Preventive Medicine, 15(4), 252-261. http://doi.org/10.1007/s12199-010-0136-3

\section{Copyrights}

Copyright for this article is retained by the author(s), with first publication rights granted to the journal.

This is an open-access article distributed under the terms and conditions of the Creative Commons Attribution license (http://creativecommons.org/licenses/by/4.0/). 